
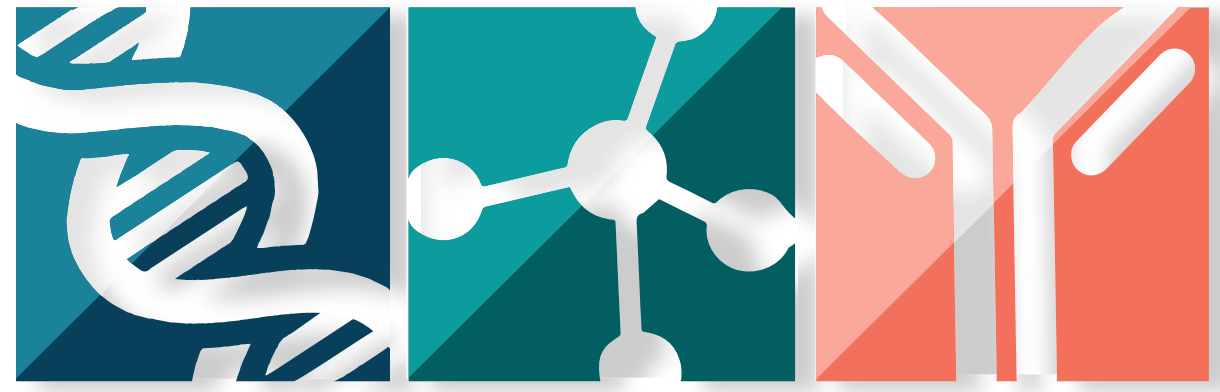

\title{
RxNet Glossary of Drug Discovery
}

$1^{\text {st }}$ Edition

Brought to you by RxNet and Future Drug Discovery

Future Drug Discov. Vol. 1 No. 1 Suppl. 1, 2019

2

Glossary information

3

Foreword

4

Scope

6

Terms \& definitions

62

Equations

66

Company profile

68

Journal information

73

Index

Publishing information 


\section{GLOSSARY INFORMATION}

\section{Editorial Panel}

The RxNet Glossary of Drug Discovery is drawn from the leading forces in medicinal chemistry and drug discovery:

Abad-Zapatero, Celerino University of Illinois at Chicago, IL, USA

Andrade, Carolina Federal University of Goiás, Brazil

Arnold, Mark Covance, NJ, USA

Caron, Giulia University of Turin, TO, Italy

Clark, David Charles River Laboratories, Harlow, UK

Duggan, Jeff Independent Consultant, USA

Ferguson, David University of Minnesota, MN, USA

Greenlee, William MedChem Discovery Consulting.

NJ, USA

Honey, Mark Sussex University, UK

Jenkins, Rand Formerly PPD Bioanalytical Labs, VA, USA (retired)

Kellam, Barrie University of Nottingham, UK

Lushington, Gerald Lushington in Silico Consulting, USA

Matta, Cherif Mount Saint Vincent University, NS,

Canada

Nixon, Gemma University of Liverpool, UK

Praveen, Bhugra University of Sunderland, UK

Prisinzano, Thomas University of Kansas, KS, USA

Tucker, Steven University of Aberdeen, UK

Zinzalla, Giovanna Karolinska Institute, Solna, Sweden

This glossary has been produced in partnership with

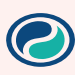

\section{FRONTAEE \\ YOUR DRUG DEVELOPMENT PARTNER}

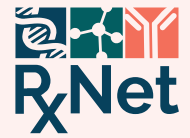

Future Science Group Ltd, Unitec House, 2 Albert

Place, London, N3 10B

Tel.: +44 (0)20 83716090

www.future-science-group.com

Disclaimer: Whilst every effort is made by the Publisher and Editorial Board to ensure that no inaccurate or misleading data, opinions or statements appear in this journal, they wish to make it clear that the data and opinions appearing herein are the responsibility of the contributor concerned. Accordingly, the Publisher, Editorial Board and their respective employees, officers and agents accept no liability whatsoever for the consequences of any inaccurate or misleading data, opinions or statements. Copyright: Readers are reminded that, under internationally agreed

\section{Future Science Group}

\author{
Chairman \\ James Drake \\ Phil Garner \\ Editorial Department \\ Editorial Director \\ Laura Dormer, \\ I.dormer@futuremedicine.com
}

Managing Director

\section{RxNet}

Publisher

Freya Leask,

f.leask@futuremedicine.com

Editor

Zoe Campbell,

z.campbell@rx-network.com

\section{Future Drug Discovery \\ Managing Editor \\ Francesca Lake, \\ f.lake@future-science.com}

Future Medicinal Chemistry

Commissioning Editor

Harriet Wall,

h.wall@future-science.com

Production

Head of Production

Zara Robinson,

z.robinson@future-science-group.com

Production Editor

Nancy Hagan,

n.hagan@future-science-group.com

Business Development \& Support

Advertising

Head of Advertising

Dionne Murray,

d.murray@future-science-group.com

Business Development Manager

Vikki Lee,

v.lee@future-science-group.com

Business Development Manager

Amy Bamford,

a.bamford@future-science-group.com

Reprints

Reprints Sales Manager

Sam Cavana,

s.cavana@future-science-group.com

Permissions

Sales Support Administrator

Stella Kirtsidou,

s.kirtsidou@future-science-group.com

copyright legislation, photocopying of copyright materials is prohibited other than on a limited basis for personal use.

Thus making copies of this supplement is a breach of the law and can be prosecuted. 


\section{FOREWORD}

RxNet glossary of Drug Discovery

The RxNet and Future Drug Discovery editorial teams are delighted to welcome you to the first edition of the RxNet Glossary.

As RxNet rebranded from MedChemNet, our scope expanded to provide a more holistic overview of the drug discovery pipeline. This was then followed by the launch of Future Drug Discovery, the latest partner journal to RxNet, which aims to cover the latest breakthrough science in drug discovery, research and development. With this, we have come together to create this glossary, which we hope will become an essential resource for everyone working within the drug discovery and related fields.

This guide will be particularly useful for those moving into the field or working with medicinal chemistry or drug discovery laboratories for the first time, and as a reference for experienced researchers writing reports, research papers or presentations.

This glossary also aims to bridge the gap between scientists working in drug discovery and the general public. With the dissemination of research across the globe, which is becoming more present in the public eye, and the general increase in interest in this exciting field, it is highly important that effort is made to educate and enhance understanding. The glossary aims to facilitate this and benefit anyone and everyone interested in learning more.

Our in-house editorial team has therefore worked closely with leading experts from industry and academia to provide a glossary that not only gives a comprehensive overview of the core, established terminologies used in medicinal chemistry and drug discovery, but one that reflects this continually and rapidly advancing field.

We are very much committed to ensuring we keep moving with this ever-changing field; hence we intend to further update this glossary, when required, to allow for the inclusion of new terms and to incorporate any changes to definitions. With this, we welcome your feedback and suggestions for future editions.

We would like to thank all the members of our editorial panel for their assistance, advice and guidance, as well as our sponsors whose support has made this first edition possible. It has been a great pleasure putting together this glossary, and we would also like to thank all the RxNet and Future Drug Discovery readers, authors, contributors and editorial board members for their continued support.

Zoe Campbell, Editor, RxNet z.campbell@rx-network.com

Francesca Lake, Managing Editor, Future Science, f.lake@future-science.com 


\section{SCOPE}

The glossary lists terms and definitions with accompanying notes where relevant concerning the classification, manufacture, application and methodologies associated with medicinal chemistry and drug discovery.

It covers:

- General terminology

- Computational chemistry and informatics

- Pharmacokinetics and toxicology

- Preclinical and early-phase clinical studies

- Rational drug design

- Drug regulation

- Biopharmaceuticals

- Small molecules

- Target discovery and validation

- High-throughput screening and assay development

- Hit-to-lead and lead optimization

- Clinical trials 


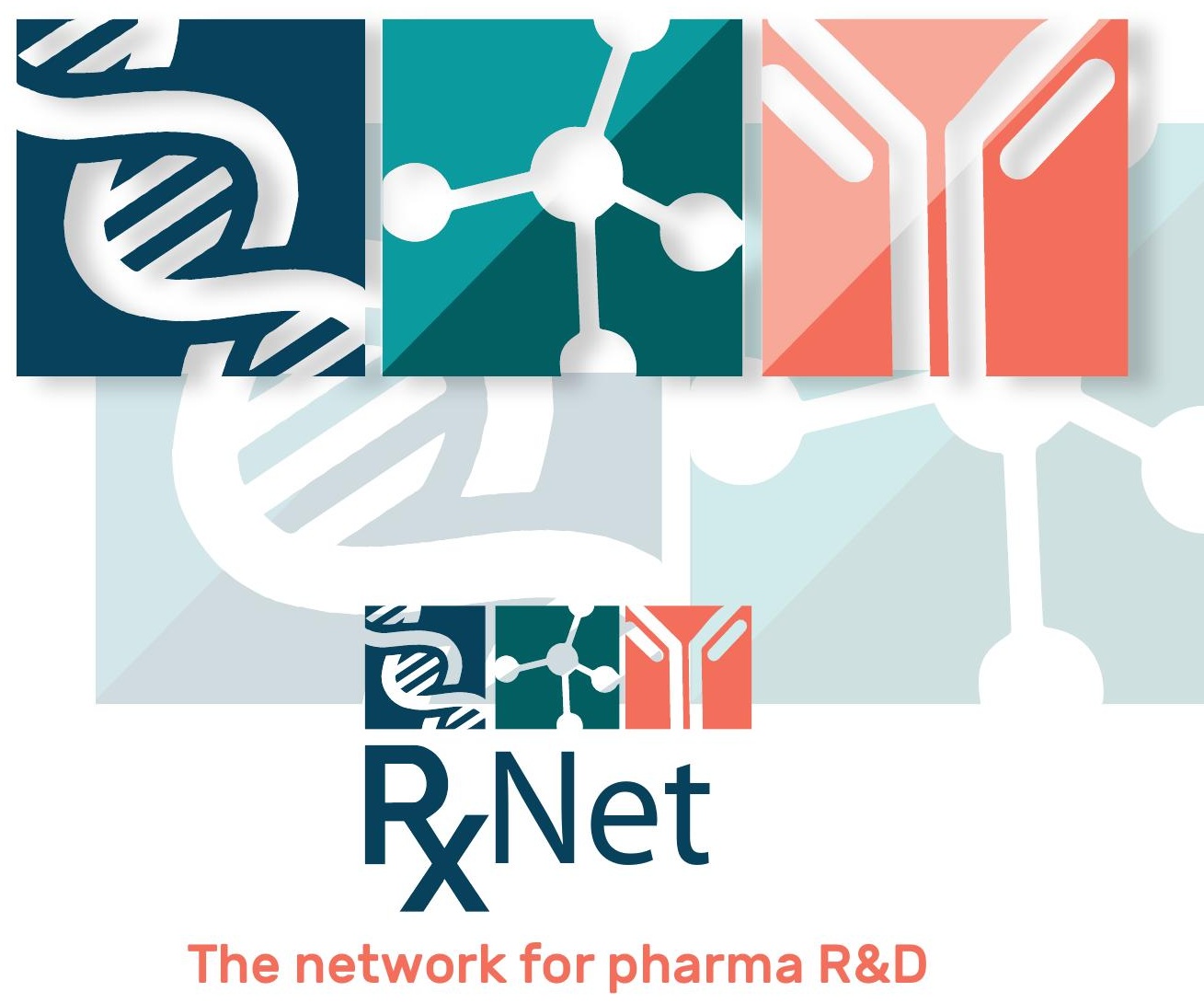

- Access exclusive content including news, expert interviews and peer-reviewed journal articles

- Connect and collaborate with industry leaders and academic experts

- Share your own research and opinions without the wait

\section{Sign up for free today at www.rx-network.com}




\section{TERMS \& DEFINITIONS}

- abbreviated new drug application (ANDA)

request to the US Food and Drug Administration (FDA) for approval of a generic drug

- absolute bioavailability

percentage of drug absorbed following non-intravenous administration in comparison to the dose administered

- absorption

uptake of a drug from the site of administration into the bloodstream

- accelerator mass spectrometry

technique that accelerates ions to very high kinetic energies before mass analysis, allowing separation and quantification of a rare isotope in the presence of an abundant neighboring isotope

- active substance

component of a medicinal product that is intended to provide pharmacological activity or any other direct effect needed in the diagnosis, cure, mitigation, treatment or prevention of disease. See also pharmacology

\section{- adjuvant}

substance added to a drug to speed up or increase the action of the main component

- advanced therapy medicinal product (ATMP)

industrially produced medicinal product classified as either a gene therapy, somatic cell therapy or tissue-engineered product 


\section{- ADME}

commonly used acronym in pharmacology and pharmacokinetics, which stands for absorption, distribution, metabolism and excretion. ADME can also be applied in conjunction with toxicology (ADMET).

- adventitious agent

contaminant, usually an infectious microorganism introduced accidentally into a cell line during the manufacturing process of a biological medicinal product

- affinity

ability of a drug to bind to its biological target, often described numerically as ka, the reciprocal of the equilibrium dissociation constant of the drug-receptor complex

- affinity-based biosensor

device able to detect the concentration of analytes by their specific binding with biotransducers, such as receptors, aptamers or antibodies

\section{- agonist}

chemical that binds to a receptor in order to initiate a biological response

- allosteric binding site

binding site on an enzyme that is not the active site

- analog

compound that has a similar structure to another compound or drug, but may display different properties

- analyte

specific chemical moiety being identified and measured, which can be an intact drug, metabolite and/or degradation product in a biologic matrix 
- ancillary material

components, reagents and materials involved in the manufacturing production of a medicinal product which are not intended to be part of the final product

- antagonist

chemical that binds to a receptor in order to inhibit its normal biological response

\section{- antibody}

protein molecule produced by the immune system in response to the presence of treatment with an antigen that is capable of binding to a specific determinant on the antigen

\section{- antibody-drug conjugate (ADC)}

biologically active drug linked, via a chemical linker, to a monoclonal antibody (mAb)

\section{- antidrug antibody (ADA)}

pre-existing or treatment-induced antibody that is capable of binding to a drug

\section{- antigen}

substance that induces the formation of antibodies in a suitable host

\section{- aptamer}

oligonucleotide or peptide molecules with highly specific binding sites for targeted molecules 


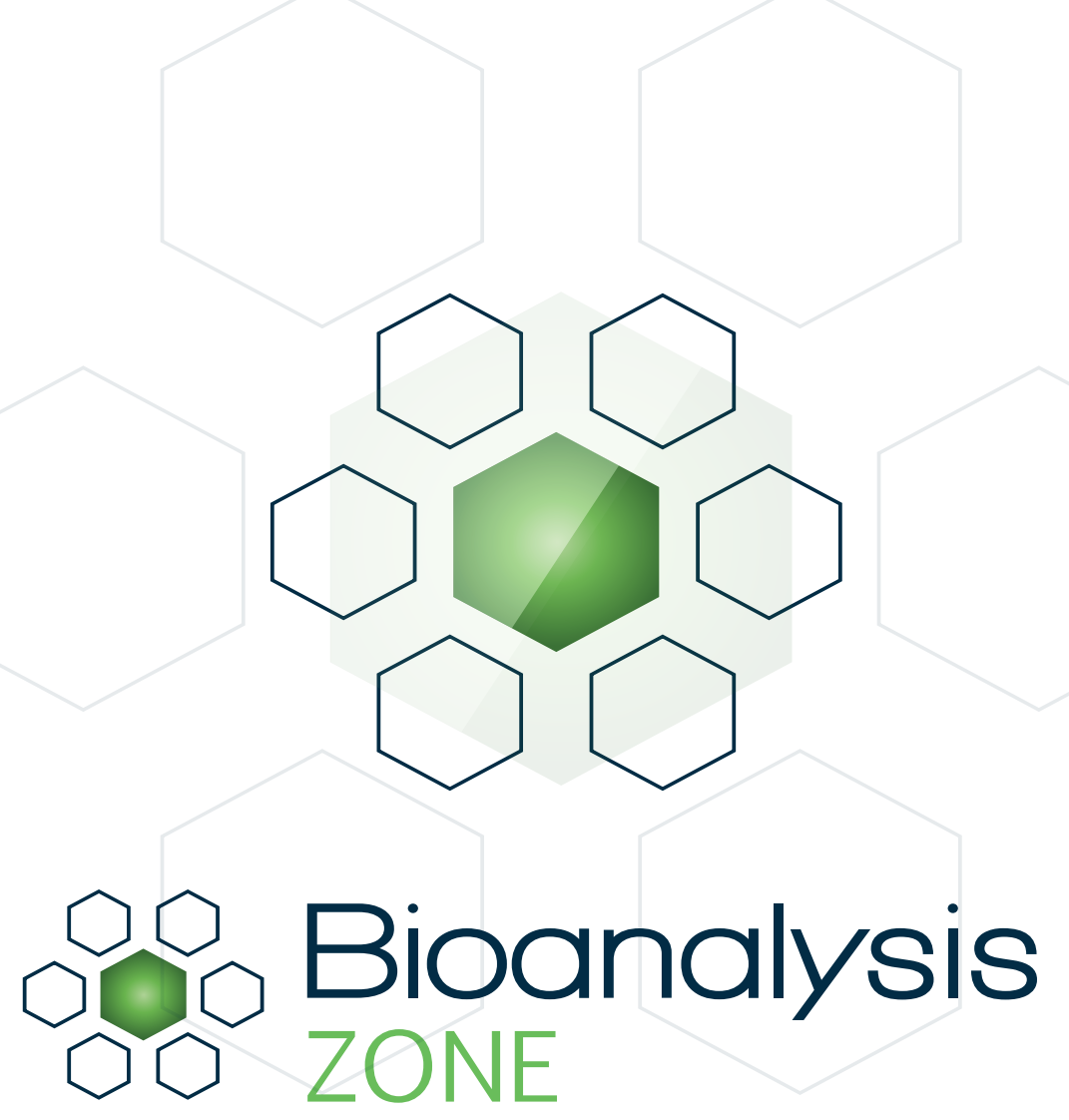

\section{Advancing the field of bioanalysis}

Bioanalysis Zone provides bioanalysts with a range of resources, including: the latest bioanalytical news; articles from Bioanalysis; exclusive interviews and commentaries from opinion leaders working within academia and the pharmaceutical industry; informative webinars; Spotlights focusing on bioanalytical 'hot topics'; a business directory; and annual awards to show recognition of outstanding achievements in the field. We also provide a forum for the community to discuss recent developments and pose any questions related to this fast moving field.

\section{Sign up for free today at www.bioanalysis-zone.com}


- assay

method to qualitatively or quantitatively assess the target's presence, amount or state of functional activity

- AtlasCBS (chemico-biological-space) server

online server for the exploration of chemico-biological databases

- audit

official systematic and independent inspection to determine whether policies and standard operating procedures (SOPs) have been put in place and are being adhered to, ensuring a clinical trial complies with regulatory requirements, reliability and integrity

- batch

fixed measure of starting material, packaging material or product processed in one or a series of processes at one time. Batching allows all repeats to be tracked to ensure uniform character and quality

- beyond rule of five compounds

compounds that do not comply with Lipinski's rule of five

- bioactive agent

agent that has a biological effect on a living organism, tissue or cell

- bioactivity

quantifiable or qualifiable extent to which a substance modulates a biochemical process

\section{- bioassay}

analysis of the potency of a drug by comparing its effects on living cells, protein targets or tissues in vitro, or in living animals in vivo, with its effects on a standard preparation 


\section{- bioavailability}

the proportion of an administered drug reaching the systemic circulation from where it can mediate its effect, often used to compare different preparations of the same drug given at the same dosage under the same conditions

\section{- bioburden}

quantity and type of microorganism living on or in an unsterilized raw material, intermediate or active substance, or finished product

\section{- biocompatibility}

ability of a material to interact with a biological system appropriately without causing toxicity, physiological reaction or immunological rejection. See also immunology

\section{- biodistribution}

spread of a biological or medicinal compound within a biological system or organism

\section{- bioequivalence}

equivalence of the plasma area under the curve (AUC) of test and reference drugs

\section{- bioinformatics}

multidisciplinary field that combines biology and computer science to analyze and interpret biological data

\section{- biologic}

\section{see biopharmaceutical}

\section{- biological agent}

bacterium, virus, parasite or fungus, genetically modified or otherwise, that can cause an infection, allergic reaction or be toxic to human health; not to be confused with biopharmaceutical

- biological medicinal product

\section{see biopharmaceutical}




\section{- biological substance}

substance or material that contains an infectious or toxic biological agent

\section{- biologics license application (BLA)}

request for authorization from the US Food and Drug Administration (FDA) to introduce and distribute a biological medicinal product across states in the USA

- biomarker

molecular or physical characteristic of a medical state, which can be reproducibly measured and evaluated to determine various biological processes in the body, which indicate disease progression or a response to a therapeutic intervention

\section{- biomolecule}

molecule, such as a peptide, protein, carbohydrate, vitamin, lipid or nucleic acid, that can be extracted from naturally occurring or recombinant organisms, tissues, cell lines or synthetic analogs

\section{- biopharmaceuticals}

diverse groups of macromolecules with therapeutic potential that are derived from living organisms or systems, also known as a biologic or a biological medicinal product

\section{- bioprocess development}

technical discipline utilizing design, engineering and optimization approaches to develop scalable and economical processes for manufacturing of cell-based or tissue-based biological products

\section{- bioprocessing}

method or process that uses living cells or tissues to attain desired products, such as preparation and preservation for storage and packaging 


\section{- biosimilar}

subsequent version of a previously approved biological medicinal product that is highly similar in safety and efficacy, also known as a 'follow-on biologic'

\section{- biostatistics}

branch of statistics that deals with data relating to living organisms

\section{- biotransformation}

metabolic or catabolic modifications made to an administered drug in a biological system

\section{- bispecific}

proteins that are composed of subunits with two different antigenbinding sites, allowing them to bind two different target species

\section{- breakthrough therapy}

status awarded by the US Food and Drug Administration (FDA) that is intended to accelerate the process of development and review of investigational medicinal products that show highly promising preliminary clinical evidence and meet an unmet medical need for a serious or life-threatening condition

\section{- capsid}

protein shell that surrounds a virus, consisting of oligomeric subunits that protect the internally contained genetic material

\section{- cell therapy}

administration of living cells to a patient for therapeutic purposes, also referred to as cytotherapy 

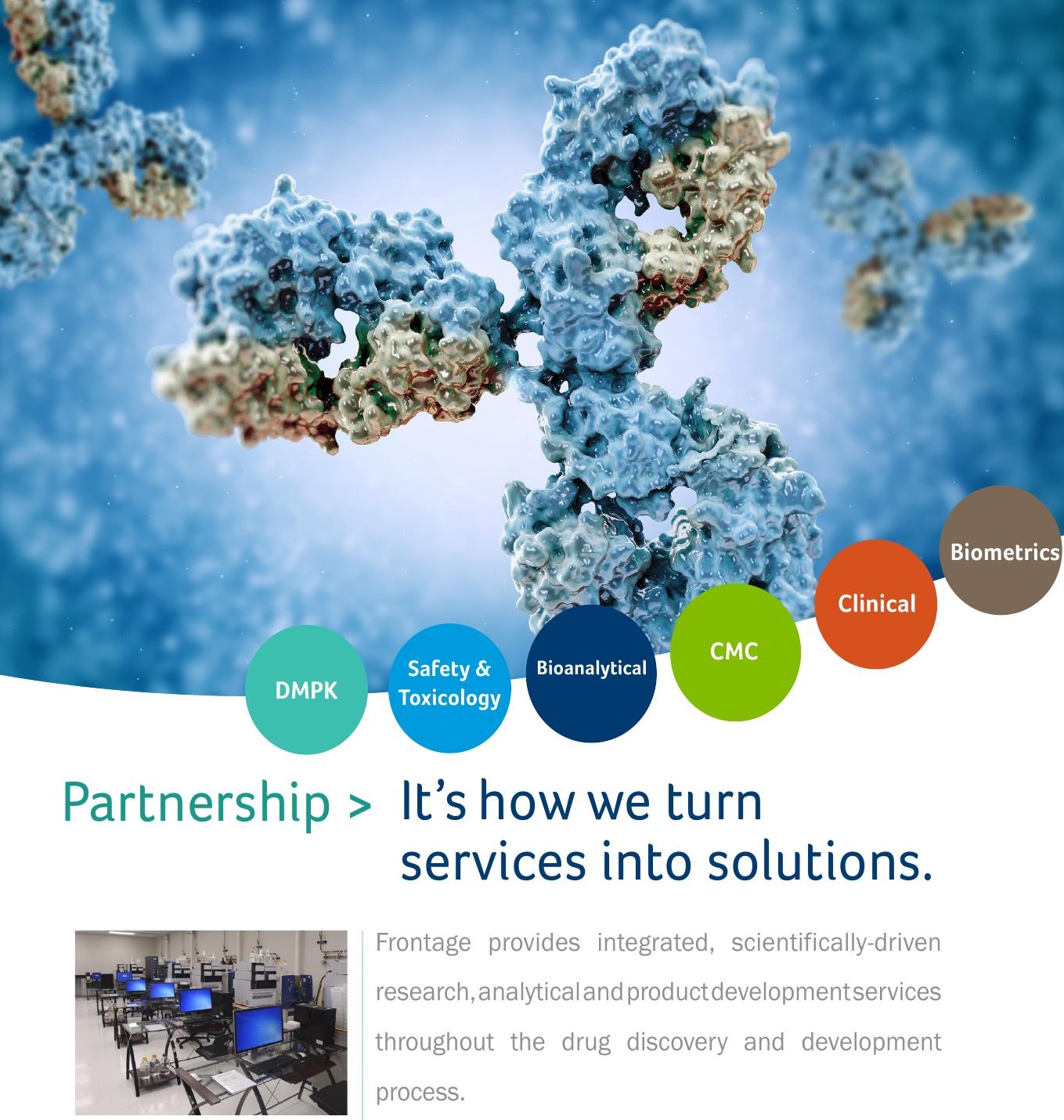

Frontage provides integrated, scientifically-driven research, analytical and product developmentservices throughout the drug discovery and development process.

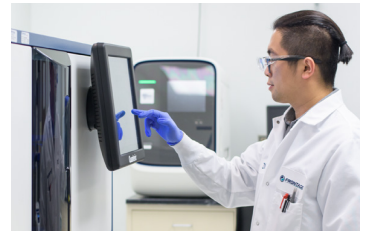

Our commitment to rigorous scientific expertise and the highest quality standards enable us to help our clients solve their most complex problems and achieve their drug development goals.

\section{(D) FRONTAGE}




\section{- cell-based neutralizing antibody assay}

method for the detection or quantification of neutralizing antidrug antibodies (ADAs), which utilizes a cell line that responds directly to the drug or to a ligand that displays altered activity in the presence of the drug

- centralized authorization procedure

procedure directed by the European Medicines Agency (EMA) leading to a marketing authorization of the medicinal product in the European Union (EU)

- chemistry, manufacturing and control (CMC) section

technical data that must be provided as part of an investigational medicinal product review

\section{- chemoinformatics}

multidisciplinary field that combines chemistry and computer science to analyze and interpret chemical data

\section{- chief investigator}

medical researcher who takes primary responsibility and charge of all the aspects of a study carried out at multiple trial sites

\section{- cleanroom (or clean facility)}

environment in which contamination from airborne particles is controlled (specified by the number of particles of a specific size per cubic meter) that is designed to minimize the introduction and generation of disallowed airborne particles inside the room, and where control over other relevant elements such as humidity, temperature and pressure is possible

\section{- clinical benefit}

clinically meaningful, positive effect of a treatment, such as the reduction of pain, an increased sense of well-being or a positive effect on how an individual functions or survives 


\section{- clinical equivalent}

therapeutic agent that fundamentally has the same effect in the treatment of disease as one or more other drugs, but may or may not be chemically equivalent or bioequivalent, sometimes referred to as a therapeutic equivalent. See also bioequivalence

\section{- clinical hold}

order given by the US Food and Drug Administration (FDA) to delay a planned clinical investigation or suspend an ongoing clinical study. See also clinical trial

\section{- clinical investigator}

medical researcher who takes responsibility to ensure that an investigation is conducted according to the signed investigator statement, the investigational plan, established ethical standards and applicable regulations

\section{- clinical laboratory improvement amendments (CLIA)} regulations that dictate standards for clinical laboratory diagnostic testing in the USA and requires laboratories to be certified

\section{- clinical outcome}

outcome that defines the physiological response to a clinical trial, or otherwise portrays how an individual feels, functions or survives in a clinical trial

\section{- clinical research organization (CRO)} independent organization contracted by the sponsor of a clinical trial to undertake one or more of the aspects required for clinical research and management of clinical trials, including protocol design, selection or monitoring of investigation, report evaluation and preparation of materials for submission to a relevant authority. See also contract research organization (CRO)

\section{- clinical sample}

sample received from a patient or healthy volunteer, for example from a clinical trial 


\section{- clinical trial}

study to evaluate the safety and efficacy of a new drug or treatment in healthy or diseased human subjects

\section{- clinical trial authorization}

permission from the appropriate regulatory authority, such as the Medicines \& Healthcare products Regulatory Agency (MHRA) in the UK or the US Food and Drug Administration (FDA), to begin the investigation of a medicinal product in a clinical trial

\section{- clinical validation}

confirmation of a patient's documented diagnosis with clinical criteria generally accepted by the medical community

- closed system

enclosed manufacturing system in which the medicinal product is not exposed to the plant, laboratory or room environment

- co-administered medicines

two or more medicinal products administered simultaneously to a subject

\section{- combination cell therapy}

combination product that contains a cell therapy product. See also combined advanced therapy medicinal product (combined ATMP)

\section{- combination product}

therapeutic or diagnostic product comprised of two or more individual products, such as a medicinal product, biological medicinal product or medical device. See also combination cell therapy and combined advanced therapy medicinal product (combined ATMP) 


\section{- combination therapy}

therapeutic strategy whereby a patient receives at least two medicinal products and/or at least two different types of therapy for a single disease or injury (e.g. chemotherapy in combination with radiation therapy in the treatment of a cancer)

\section{- combined advanced therapy medicinal product (combined} ATMP)

medicinal product incorporating one or more medical devices or active implantable medical devices, which contains either a cellular or tissue part with viable cells or tissues, or a cellular or tissue part with non-viable cells or tissues, and will often act in a way that is independent of the primary actions of the referred to devices. See also advanced therapy medicinal product (ATMP), combination cell therapy and combination product

\section{- comedication stability}

process of assessing the stability of a drug or medicinal product in the presence of another compound that is administered together with that medicinal product

\section{- comparability}

evaluation of any manufacturing process changes to assess the impact on the quality, non-clinical and/or clinical data of a drug or its components

\section{- comparable}

verdict that the change in the manufacturing process of a medicinal product has no negative effect on the safety, bioavailability or efficacy of the product, which can be based on analysis and sometimes on non-clinical or clinical data

\section{- competent authority}

any person or organization with legally delegated or invested authority, jurisdiction, power or capability to perform a specific assigned obligation or function. Also referred to as a national competent authority (NCA), since authorities in different countries have varying responsibilities 
- compound library

collection of stored chemicals usually used in high-throughput screening or industrial manufacture

- computer-aided (or -assisted) drug design (CADD)

drug design that relies on computer modelling and where large compound libraries are screened to predict active compounds, which may involve virtual screening, virtual library design, lead optimization and de novo design

- conformational analysis

exploration of energetically favorable molecule conformations using molecular mechanics, molecular dynamics, quantum chemical calculations or analysis of experimentally determined structural data

\section{- confounding factor}

variable that can influence the association of two further variables being studied, such as age

\section{- contained use}

activity involving genetically modified microorganisms under containment, whereby the contact of the organisms with the environment or general population is limited via physical, chemical and/or biological barriers

\section{- contaminant}

impurity of a chemical or microbiological nature, or foreign matter, not intended to be present in or on a raw material (including compounds that can leach from sources such as plastic containers), intermediate or active substance introduced during production, packaging and repackaging, sampling, storage or transport

\section{- contamination}

unwanted introduction of chemical or microbiological impurities or foreign bodies into substrate, intermediates or active substances that may occur during production, packaging and repackaging, sampling, storage or transport 
- continued process verification

collection and analysis of data on a production process for the process to remain in control, performance standards to be met and product outputs to be of desired quality

\section{- contract development and manufacturing organization}

(CDMO)

independent organization contracted to provide research and manufacturing services to other companies or parties working in the pharmaceutical, biotechnology and medical device industries

- contract manufacturing organization (CMO)

independent organization contracted to provide specific manufacturing services to other companies or parties working in the pharmaceutical, biotechnology and medical device industries

\section{- contract research organization (CRO)}

independent organization contracted to provide clinical trial and other research support services to other companies or parties working in the pharmaceutical, biotechnology and medical device industries, such as protocol design, selection or monitoring of investigations, report evaluation and preparation of materials for submission to a relevant authority. See also clinical research organization (CRO)

\section{- control (subject/group)}

subject/group in an experiment to which the medicinal product being tested is not applied, thereby serving as a standard of comparison for evaluating experimental observations as a result of the factor

\section{- cost of goods sold (COGS)}

cost to make and sell a particular product; for example, all the costs to safely manufacture, test, document, store and transport a medicinal product, which must be minimized to get medicinal products to market 


\section{BioTechniques}

ISSN: 0736-6205

Frequency per year: 12

\section{BioTechniques}

reatures

Grow your
own brain

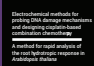

(2)
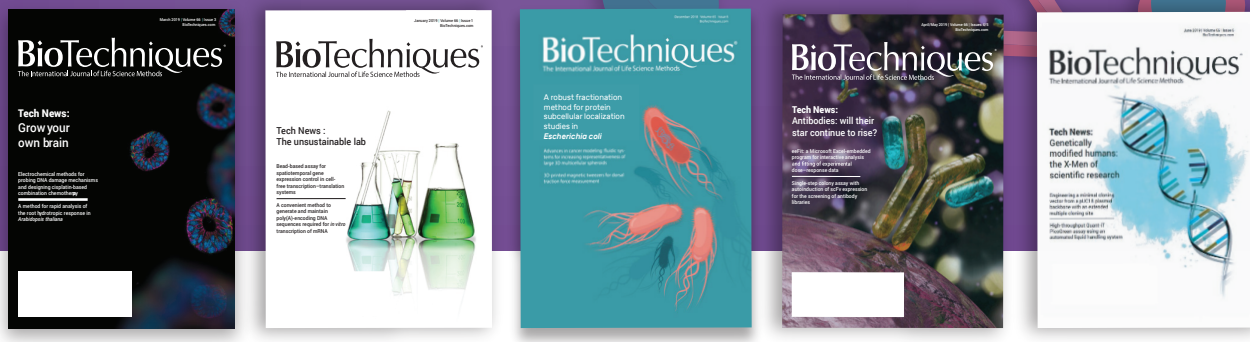

IMPACT FACTOR:

BioTechniques is a MEDLINE-indexed, peer-reviewed, open access journal that provides the life science research community with an invaluable resource to access latest methods, techniques and protocols.

\section{Your leading resource for peer-reviewed laboratory methods since 1983}

\section{INDEXING}

- Biological Abstracts • BIOSIS Previews • Current Contents ${ }^{\circledast} /$ Life Sciences $•$ Directory of Open Access Journals (DOAJ)• EMBASE/Excerpta Medica - Essential Science Indicators • Journal Citation Reports/Science Edition • MEDLINE/Index Medicus • Research Alert • Science Citation Index ${ }^{\circledast}$ Science Citation Index Expanded $\left(\right.$ SciSearch $\left.^{\circledast}\right) \cdot$ Scopus $^{\circledR}$

\section{Submit your paper}

j.martin@future-science-group.com

\section{FUTURE SCIENCE part of}


- cost-benefit analysis

systematic approach used as a decision-making tool when deciding whether the benefits justify the associated costs by quantifying and analyzing economic factors and beneficial consequences of a project or program

\section{- CRISPR/Cas9}

genome-editing technology used to modify genes whereby the CRISPR sequences guide the system to target DNA, which is then cut by Cas9 enzymes

\section{- cross-contamination}

unintended presence of a cell or a material in another cell or material

- cytotherapy

see cell therapy

- cytotoxicity

damaging effect a compound or material has on living cells or cellular components

- de novo design

method of drug discovery where a 3D structure of the target site is used to predict a chemical structure that will have a high affinity for the site, thus identifying (lead) compounds

- disease-in-a-dish

manufactured disease model formed from cultured cells that express the properties of a disease and are usually generated from induced pluripotent stem cells derived from individuals with a specific disease

\section{- distribution}

movement of drug absorbed into the bloodstream between tissue compartments as it circulates throughout the body

\section{- DNA construct}

artificial DNA molecule synthesized in vitro for transfection into target cells or tissue 


\section{- DNA extraction/isolation}

isolation of DNA from a sample using chemical or physical methods

- DNA fingerprinting

visualization of a pattern of genetic elements which represents a unique DNA sequence

- DNA fragmentation separation of DNA sequences into smaller fragments, either naturally or synthetically

- DNA methylation addition of methyl groups to a DNA sequence, often altering the activity of the sequence, either naturally or synthetically

- DNA polymerase

enzyme that catalyzes the condensation reaction of two nucleotides, forming a DNA strand

- DNA profiling

process of characterization of DNA sequences which permits the identification of an individual organism or strain

- DNA short tandem repeat profiling (DNA STR profiling) detection of STRs as a DNA profiling technique

- dosage regimen

schedule under which drugs are administered in order to maintain its plasma concentration within the therapeutic window

- dose

measured quantity of a therapeutic drug taken at one time 


\section{- dose-response curve}

graph that describes the response of a biological system, typically the fraction of drug bound to its target, versus drug concentration, expressed as log[dose]

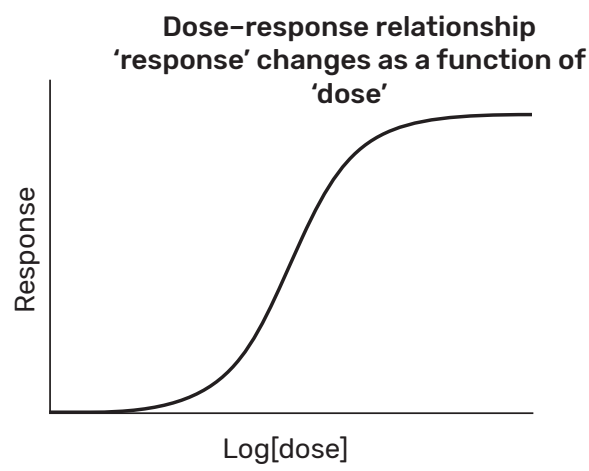

- dosing interval

time between the administration of doses of a drug

- dosing vehicle

molecule that facilitates a drug's absorption or administration within the body

- downstream processing

stages of processing that occur after the initial production of the material, such as purification of a drug after its initial synthesis

- drug

substance that induces a physiological effect on the body upon administration; must be approved by a government agency (e.g. US FDA or MHRA)

- drug master file

document containing information about facilities, processes or articles used in the manufacturing, processing, packaging and storing of drugs 


\section{- drug metabolism}

chemical modification of drugs through enzyme-mediated reactions within the body, which may involve oxidation, reduction, hydrolysis, hydration, conjugation and migration

\section{- drug-drug interaction}

interference of one medicinal product with the action of another, either increasing, decreasing or altering its effects

- druggable

biological target that is thought to be susceptible to the binding of drugs

- eastern blot

analytical technique which allows the detection of post-translational protein modification such as glycosylation, lipoylation and phosphorylation

- efficacy follow-up

method used to establish the efficacy of a medicinal product through the systematic collection and collation of data

- elimination half-life

pharmacokinetic parameter defined as the time taken after equilibrium is reached to reduce the drug concentration in the plasma by one half

\section{- end point}

defined parameter which is measured to evaluate the outcome of an intervention

\section{- enzyme}

macromolecular biological catalyst which speeds up the rate of a chemical reaction in a living organism

- enzyme induction

interference of a medicinal product or chemical entity with an enzyme which causes the expression of the enzyme, increasing the rate of an enzyme-catalyzed reaction 
- enzyme inhibition

interference of a medicinal product or chemical entity with an enzyme, which reduces the activity of the enzyme, decreasing the rate of an enzyme-catalyzed reaction

- ethics committee

independent body of healthcare professionals and non-medical members that oversees ethical aspects of studies involving human subjects in order to protect their rights, safety and well-being

\section{- European Medicines Agency (EMA)}

scientific agency responsible for the protection of public and animal health in the European Union (EU) through the scientific evaluation and supervision of medicines for human and veterinary use

\section{- excipient}

inactive substance added to a drug product to facilitate absorption and distribution of the drug

\section{- excretion}

process by which compounds and their metabolites are eliminated from the body

- ex vivo

occurring outside a living organism

- false negative

incorrect result indicating a parameter, such as a finding, condition or disease, is not present

\section{- false positive}

incorrect result indicating a parameter, such as a finding, condition or disease, is present

- first-in-class

novel drug which utilizes a unique mechanism of action when interacting with its target 
- first-pass effect

reduction of a medicinal product concentration due to metabolism of the medicinal product before it reaches systemic circulation

\section{- flow cytometry}

method used to identify cells and their components by analyzing the light scattering and fluorescence from a stream of single cells flowing through a laser beam

\section{- fluorescence-activated cell sorting (FACS)}

type of flow cytometry where a heterogeneous mixture of cells is sorted into two or more containers based on their specific light scattering and fluorescent characteristics

\section{- fluorescence imaging}

visualization of fluorescent dyes or proteins to monitor or observe biological systems

\section{- fluorescent in situ hybridization (FISH)}

method where fluorescent probes are used to bind to complementary DNA sequences, determining the location or the absence of a specific DNA sequence on a chromosome

\section{- fluorophore}

molecule that emits light on excitation and can be used to label and subsequently monitor substances such as proteins

\section{- Food and Drug Administration (FDA)} agency within the US Public Health Service that is responsible for approving the safety, efficacy and marketability of medicines, among other health-related services

\section{- formulation}

process during which an active drug is combined with different chemical substances to form the final medicinal product 


\section{- Förster resonance energy transfer (FRET)}

mechanism describing the energy transfer from one (donor) fluorophore to another (acceptor) fluorophore

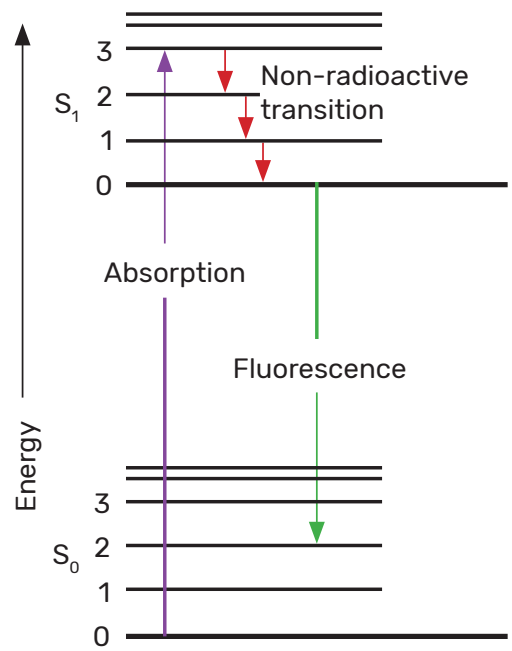

Ground state

\section{- fragment-based drug design}

method of drug discovery based on identifying small fragments that bind weakly to a biological target, followed by the growth or combination of fragments to produce a lead compound that displays higher affinity

\section{- free drug}

drug in the body that is not bound to a carrier protein or other molecule and therefore is able to exert its biological effect

\section{- gene editing}

insertion, deletion, modification or replacement of sequences in a genome

\section{- gene expression}

process by which molecular products are synthesized from their corresponding genes; for example, DNA is transcribed to produce RNA, which can then be translated to form proteins 


\section{- gene expression profiling}

process of measuring the level of messenger RNA (mRNA) showing the pattern of genes expressed at the transcription level

\section{- gene therapy}

therapeutic technique whereby nucleic acids are delivered into cells in order to modify or replace genes for the purpose of treating disease

\section{- generic}

pharmaceutical compound which has the same active ingredient as the original drug, but may differ in features such as formulation, excipients, manufacturing process or appearance

\section{- generic drug}

drug created with the same chemical structure of an existing brandname drug, equivalent in dosage form, safety, strength, route of administration, quality and performance characteristics, which can enter the market once the patent of the original drug has expired

\section{- genetic engineering}

process of altering the DNA in a genome

\section{- genetic locus}

location of a gene or specific DNA sequence on a chromosome

\section{- genetic mapping}

method used to describe the relative positions and distances between genetic markers on a chromosome

\section{- genetic marker}

DNA sequence which has a known location on a chromosome and can be used to identify individuals or species

\section{- genome}

total set of genes or genetic material in an organism

\section{- genome library}

collection of the total set of genes or genetic material in an organism, which is often used for sequencing 
- genomic modification

intentional insertion, removal, modification or replacement of DNA in a genome

\section{- genotype}

genetic material responsible for a particular phenotype

- genotyping

identification of a gene by comparison of DNA sequences

- glycosylation

condensation reaction between a carbohydrate and a hydroxyl (or other nucleophilic) group of another molecule, resulting in a glycosidic bond

\section{- good clinical practice (GCP)}

standard for the design, conduct, performance, monitoring, auditing, recording, analysis and reporting of clinical trials or research, which provides assurance that the data or results are credible and accurate

- good laboratory practice (GLP)

principles designed to ensure the quality, integrity and validity of non-clinical laboratory research intended for developing and/or marketing products regulated by government agencies

\section{- good manufacturing practice (GMP)}

minimum quality standards required in the production of cell therapy products, medicinal products, medical devices, diagnostic products, food products and active substances; as laid out by national and international regulatory agencies on public health care

\section{- high-throughput screening}

method by which large compound libraries are tested for activity against specific target(s) 


\section{- high-resolution mass spectrometry (HR-MS)}

mass spectrometry technique capable of separating ions or mass fragments from a sample and measuring them with a very narrow spectral bandwidth, yielding high specificity

- hit

identified molecule that has the ability to bind to its target to bring about a biological response, which may require further development

\section{- hit confirmation}

series of methods/assays applied to an identified hit molecule to confirm its structure and activity profile

\section{- hit identification}

process to analyze molecules to discover which has activity against a target

\section{- hit-to-lead/lead generation}

stage in early drug discovery where small-molecule hits are evaluated and undergo limited optimization to identify promising lead compounds

- $I C_{50}$

measure of the potency of an inhibitor on its biological target, quantitatively measured as the concentration of inhibitor required to reduce the target's binding ability or function by $50 \%$, which is dependent on the concentration of the target

- immunocytochemistry

antibody-based labeling method where specific proteins are labeled, typically with a fluorophore, to allow their location to be visualized

\section{- immunogenicity}

ability of an administered substance to induce an, often adverse, immune response in the patient. See also immunology

\section{- immunology}

field of study related to the immune system or its responses 
- immunomodulation

modification of a natural immune response through induction, amplification, attenuation or prevention. See also immunology

\section{- immunotherapy}

therapeutic strategy to treat disease by activating or suppressing the immune system. See also immunology

\section{- impurity}

unwanted component of a product

\section{- in silico}

experiments performed on a computer

- in vitro

experiments performed outside the normal biological context of an organism, typically in chemical or biochemical assays

- in vivo

experiments performed within the normal biological context of an organism

- in-process control

checks that are carried out before the drug manufacturing process is completed, designed to ensure the process proceeds as desired and the final product will meet given specifications

\section{- incurred sample}

study sample collected from subjects or animals participating in a study that may be used later for confirmatory reanalysis

\section{- incurred sample reanalysis}

reanalysis of a portion of preclinical or clinical samples from subjects to determine whether the original analytical results are reproducible. See also reproducibility 


\section{- informed consent}

documented voluntary agreement to participate in a clinical trial or study, made by a person or their legal representative, after they have been informed of the nature, importance, implications and risks associated with it

- inhibitory dose

dose of a drug that causes a defined extent of inhibition of a specific target

- intellectual property

intangible creative assets which can be protected by law with patents, copyrights and trademarks

\section{- interim data}

report of results and their evaluation based on analyses performed during preliminary trials or experiments

\section{- intermediate}

molecule resulting from a reaction in the manufacturing process, which requires further modification to achieve the final product

\section{- International Organization for Standardization (ISO)}

non-governmental agency which provides a source of international standards for ensuring consistency in materials, products, processes and services across numerous industries

- intravascular administration

route of administration where the drug is introduced into the bloodstream directly

- intrinsic clearance

predicted unrestricted maximum clearance of a free drug by an elimination organ such as the kidney

- investigational device exemption decision made by the US Food and Drug Administration (FDA) that allows an investigational device to be used in a clinical trial for the purpose of collecting safety and efficacy data which can be used to support a premarket approval application 
- investigational medicinal product (IMP)

active substance or placebo in its pharmaceutical form which is being used or tested in a clinical trial

- investigational new drug (IND)

substance approved by the US Food and Drug Administration (FDA) for testing in human clinical trials

- investigational new drug (IND) application

means by which a pharmaceutical company obtains permission to administer a medicinal product to humans in a trial

\section{- ion-exchange chromatography}

method of separating molecules based on their charge, which enables the separation of proteins and amino acids and other charged polar molecules, which are difficult to separate via alternative methods

$\cdot \mathrm{Kd}$

dissociation constant, which measures the ability of a drug-target complex to separate

- $\mathrm{Ki}$

inhibitory constant, which describes the affinity of a drug for its target, independent of the concentration of the target

- lab-on-a-chip

device that combines multiple laboratory techniques into a system which fits onto a single integrated circuit of up to a few centimeters in size and allows for automated processes such as high-throughput screening, and rapid heating and mixing

\section{- lead candidate}

compound or molecule that shows appropriate target selectivity and potency, has a strong therapeutic potential and justifies further development 


\section{- lead optimization}

chemical modification of lead compounds to enhance their potency, selectivity, pharmacokinetic or ADMET properties, with the goal of producing a viable drug candidate

- ligand

substance that forms a complex with a biomolecule to serve a biological purpose

\section{- ligand-based drug design}

drug design approach which relies on knowledge of what binds to the target and is often used in the absence of reliable 3D protein structural data

\section{- ligand efficiency}

measure of the binding energy per non-hydrogen atom of the drug to its target

\section{- Lipinski's rule of five (or Pfizer's rule of five or rule of}

\section{five or Ro5)}

set of criteria used to evaluate an orally administered drug candidate which states that, in general, an orally active drug will have no more than one violation of the following criteria:

- no more than five hydrogen bond donors (the total number of nitrogen-hydrogen and oxygen-hydrogen bonds)

- no more than 10 hydrogen bond acceptors (all nitrogen or oxygen atoms)

- a molecular mass less than 500 Daltons

- an octanol-water partition coefficient logP not greater than 5

\section{- lipophilicity}

parameter describing solubility and membrane permeability, which is important when considering a drug's absorption and distribution throughout the body 


\section{- liposomal drug}

medicinal product that is encapsulated in a vesicle possessing at least one lipid bilayer, which modifies the pharmacokinetic and pharmacodynamic properties of the product for the purpose of enhancing characteristics such as biocompatibility and absorption

- liquid chromatography

separation technique that separates analytes between a mobile phase and a stationary phase to separate the different components in the mixture

\section{- live-cell imaging}

study of living cells using time-lapse microscopy, enabling scientists to obtain a better understanding of biological function

\section{- Iymphocyte}

type of white blood cell that determines the immune response to a pathogen and exists as two cell types: B cells, which are memory cells that produce antibodies against foreign cells; and T cells, which attack body cells that have been infected with viruses

\section{- magnetic-based cell sorting}

method for the isolation of cells, proteins, DNA or RNA from a heterogeneous mixture which utilizes antibody-coated magnetic beads that bind to specific surface receptors on molecules of interest and separate them from the sample using a strong magnetic field

\section{- manufacture}

process by which a product is produced, including stages to isolate, grow, modify, scale up, test and/or store chemical or biological materials as necessary for clinical use

\section{- marketing authorization}

granting of permission by the relevant government authority for a medicinal product to be marketed and sold. See also new drug application (NDA), investigational new drug application (IND) and biologics license application (BLA) 
- mass spectrometry

method for the quantification and identification of small molecules and biomolecules in pure samples and complex mixtures by ionizing the species and seperating the ions via their mass-to-charge ratio

\section{- master schedule}

good laboratory practice requirement for all non-clinical laboratory studies containing information such as the test system, the nature of the study, the date the study was initiated, the current status of each study, the identity of the sponsor and the name of the study director

\section{- matrix}

non-analyte portion of a sample to be analyzed

- maximum tolerated dose (MTD)

highest dose of a medicinal product that does not cause unacceptable side effects

\section{- mechanism of action}

method by which a drug produces its pharmacological effect. Also referred to as 'mode of action'. See also pharmacology

\section{- medical device}

apparatus, appliance, software, material or other article intended to be used, alone or in combination for the diagnosis, prevention, monitoring, treatment or alleviation of disease or disability caused by injury, which achieves its intended action through means other than pharmacology, immunology or metabolism

\section{- medicinal product}

product that is intended to treat or prevent disease, to make a medical diagnosis or to restore, correct or modify physiological function through pharmacological, immunological or metabolic means. See also pharmacology, immunology or metabolism 


\section{- Medicines and Healthcare products Regulatory Agency}

\section{(MHRA)}

UK agency responsible for ensuring that medicinal products and medical devices work and are acceptably safe

\section{- metabolic biomarker}

endogenous metabolite that changes concentration in response to disease or therapy and can be used for the purpose of diagnosis, disease subcategorization, prognostication and prediction of therapeutic sensitivity to treatments

\section{- metabolism}

chemical breakdown of drugs in the body, usually through specialized enzymatic systems

\section{- metabolite}

intermediate or product of the metabolism of exogenous or endogenous substances

\section{- metabolite profiling}

measurement of all metabolites and their intermediates in a biological system

\section{- metabolites in safety testing (MIST)}

detection, confirmation and comparison of the exposure of drug metabolites observed in human clinical trials with those observed in animal studies for the establishment of human safety parameters

\section{- method}

stepwise, systemic description of all procedures used to accomplish a task or result

\section{- microfluidics}

manipulation and control of the behavior of very small volumes of liquids, usually between microliters $\left(10^{-6}\right)$ and picoliters $\left(10^{-12}\right)$. See also lab-on-a-chip 


\section{- microRNA}

class of naturally occurring non-coding RNA found in plants, animals and some viruses, which are involved in the regulation of gene expression and RNA silencing

- microsampling

process of collecting and analyzing minute samples, no more than $10-20 \mu \mathrm{l}$

- mimetics

compounds that display similar pharmacological effects to another compound

- minimal manipulation

processing of cells or tissue that doesn't alter their relevant biological characteristics

\section{- molecular cloning}

set of techniques utilized to insert recombinant DNA into a plasmid or viral vector, leading to the production of numerous copies of the desired DNA fragment. See also DNA fragmentation

\section{- molecular docking}

tool used in structural molecular biology and computer-aided drug design to allow for the prediction of the preferred binding mode(s) of a ligand to a protein of known 3D structure, resulting in the formation of a stable complex

\section{- monoclonal antibody}

antibody produced from cloned cells originally derived from a single lymphocyte

\section{- multiple ascending dose (MAD)}

study type in which a medicinal product is administered to trial subjects repeatedly at intervals shorter than those required for the previous dose to be completely metabolized for the purposes of studying the pharmacokinetics, pharmacodynamics safety and tolerability of a medicinal product. Also known as 'multiple rising dose (MRD)' 
- multi-site study

study that conducts phases at various sites

- multiplicity of infection (MOI)

ratio of infectious agents, such as viruses or bacteria, to infection targets, such as host target cells

\section{- National Institutes of Health (NIH)}

primary agency of the US government responsible for promoting and supporting biomedical and public health research

\section{- National Institute for Health and Care Excellence (NICE)}

national body that provides guidance on the use of health technologies within the UK National Health Service, clinical practice and the public sector fields of health promotion, ill-health avoidance and social care services

- negative predictive value (NPV)

probability that a subject that screens negative to a diagnostic test doesn't have the disease

\section{- neutralizing antibody (NAb)}

antibody that defends a cell from a pathogen by binding to an antigen and blocking its biological effect

\section{- new drug application (NDA)}

request to the US Food and Drug Administration (FDA) for permission to sell or market a pharmaceutical product in the USA

\section{- next-generation sequencing (NGS)}

umbrella term that covers all modern sequencing technologies, also known as high-throughput sequencing

- non-cell-based neutralizing antibody (NAb) assay

analytical technique used to assess the presence of neutralizing antidrug antibodies (ADA) in a sample without using intact cells for analysis, and to assess the efficacy and safety of a medicinal product 


\section{Therapeutic Delivery}

ISSN: 2041-5990

Frequency per year: 12

\section{THERAPEUTIC DELIVERY COVERS KEY AREAS SUCH AS:}

" Therapeutic Delivery is a unique journal due to its focus on translational research for disease treatment. While there are other journals that may cover the delivery aspects, and journals that cover pharmaceutically relevant therapeutic aspects, the emphasis on the combination of these, and the translational nature of this journal fills a particular niche."

- Carol Lim, University of Utah

\section{INDEXING}

MEDLINE ${ }^{\circ} /$ Index Medicus • Chemical Abstracts EMBASE/ Excerpta Medica $\cdot$ Emerging Sources Citation Index (Web of Science) \& Scopus ${ }^{\bullet}$

www.future-science.com
- Delivery of small molecule drugs, vaccines, radionuclides, proteins, peptides, genes, siRNA, nucleotides, stem cells and diagnostic probes

- Targeting at the molecular, cellular, organ and systemic levels

- Techniques for crossing biological barriers

- Methods for enhancement of pharmacokinetic profiles

- Biodynamic and bioresponsive delivery

- Stimuli triggered delivery

- Parenteral delivery

- Nanotechnology

- Personalized therapeutic delivery

- Combination products and delivery devices

- Intellectual property, competitor intelligence and partnering news

- Cost/benefit analyses

- In vitro, in vivo and in silico delivery studies

- Emerging technologies 


\section{- non-clinical study}

method of collecting data on an investigational medicinal product (IMP) through in vitro or in vivo animal studies to evaluate potential for clinical use or development

\section{- non-coding RNA (ncRNA)}

RNA molecule that is not translated into a protein and usually functions to regulate gene expression at the transcriptional and post-transcriptional levels

\section{- northern blot}

analytical technique used to study gene expression based on available RNA, whereby the RNA is separated by size using electrophoresis and then detected using a hybridization probe

\section{- nuclear imaging}

technique used in vivo to image trace amounts of a candidate drug in its radiolabeled form

\section{- off-label use}

use of a drug for other than its approved purpose, age group, dosage form or route of administration

\section{- optical imaging}

use of light, in the wavelength range from ultraviolet to near infrared, to investigate and visualize molecular and cellular functions within biological systems

\section{- oral administration}

route of administration where a substance is taken through the mouth, including buccal, sublingual and prelingual administrative routes or by gavage

\section{- organ-on-a-chip}

single device consisting of individual chambers connected by microfluidic channels for enclosing, contacting and culturing multiple types of cells, tissues or mini-organs, designed to recreate the microarchitecture of an organ in vitro in order to mimic biological function in vivo 
- organoid

artificially grown 3D cluster of cells derived from pluripotent stem cells that has some attributes of a specific organ and can be utilized in drug testing or disease modeling

\section{- orphan drug}

medicinal product used for the diagnosis, prevention or treatment of a rare condition or disease that remains commercially undeveloped due to economic reasons. An active clinical compound for which the biological target is unknown

- orthosteric binding site

primary, unmodulated ligand binding site on a receptor

\section{- orthosteric regulation}

binding of a chemical to the primary or active site of an enzyme in order to either suppress or induce a biological response

\section{- paratope}

part of an antibody that recognizes an antigen

\section{- partial agonist}

medicinal product or drug that, under specified conditions, cannot elicit as large an effect - even when used at high concentrations as another, (full, agonist), acting through the same receptors in the same tissue

\section{- pathogen}

agent or microorganism that can cause disease

\section{- peptidomimetic}

molecule comprised of non-peptidic units that is able to bind to its target in a way that mimics a natural protein

\section{- performance indicator}

criterion or measurement of quality used to quantify the performance of a process, system or organization, also known as performance metrics 
- permeability

ability of a compound to pass across biological membranes, a key factor that influences the absorption and distribution

\section{- pharmaceutical}

substance that has been manufactured for the purpose of use as a medicinal product

\section{- pharmacodynamics (PD)}

study of the physiological effects produced by the interaction of drugs pharmacologically active with their target and resultant mechanism of action, including the biochemical and physiological factors that could influence that effect

\section{- pharmacoeconomics (PE)}

study of the value of one pharmaceutical product compared with another

\section{- pharmacokinetics (PK)}

study of the movement of a drug in the body and how it is processed, which includes absorption, distribution, metabolism and excretion

\section{- pharmacology}

study of the scientific and clinical application of drugs, including their composition, actions, uses and effects

\section{- pharmacophore}

part of a molecule possessing the necessary steric and electronic features needed for a particular biological or pharmacological interaction

- pharmacovigilance (PV)

pharmacological science focused on studying the detection, analysis, understanding and prevention of adverse effects or issues associated with medicinal products

\section{- phase I clinical trial}

first in-human clinical trial phase used to evaluate the safety and toxicity of a new treatment, also providing preliminary efficacy data 
- phase II clinical trial

clinical trial phase used to evaluate the efficacy and safety of a new treatment, whereby the new treatment is usually administered to patients with the disease/condition for which the treatment is being developed, often divided into Phase IIA and Phase IIB to evaluate dosing requirements and clinical efficacy of a drug, respectively

\section{- phase III clinical trial}

clinical trial phase used to evaluate the efficacy and safety of a new treatment in a large number of patients and to compare this to the current standard-of-care treatment, which is often randomized

- phase IV clinical trial

post-authorization clinical trial phase performed in many patients to determine any rare or long-term adverse effects of a new treatment

\section{- phosphorylation}

the addition of a phosphoryl group to a pre-existing molecule or compound

\section{- photoacoustic imaging}

imaging technique whereby non-ionizing laser pulses are delivered into biological tissues, causing thermoelastic expansion, which then generates ultrasound waves that are detected by a transducer to produce images of optical absorption contrast within tissues

- pKa

measure of the degree of ionization of a drug. Most drugs will ionize in an aqueous solution to give weakly acidic or basic solutions

- placebo

inert substance with no physiological effect

\section{- placebo-controlled trial}

controlled trial whereby a separate control group receives a placebo in order to distinguish between actual therapeutic action and the suggestive effect of the medicinal product under study 
- placing on the market

supplying or making a product available on the market for the first time for clinical use, either for a fee or free of charge; can be done by the manufacturer or the importer

- plasma protein binding

extent to which a pharmaceutical binds to endogenous plasma proteins, which can affect the efficiency of the pharmaceutical and is often expressed as the percentage of the drug that is protein-bound

- polymerase chain reaction (PCR)

technique used to enzymatically, rapidly amplify a single or multiple copies of a particular DNA sequence using short DNA sequences called DNA primers

- positive predictive value (PPV)

probability that a subject who screens positive to a diagnostic test does actually have the disease

- potency

dose of medicinal product that produces a given biological response OR expression of the activity of a drug or medicinal product, in terms of the concentration or amount needed to produce a defined biological effect

- pre-market approval (PMA)

process by which the US Food and Drug Administration (FDA) evaluates the safety and effectiveness of Class III medical devices that have been considered high risk

- preclinical development (PCD) see preclinical trial

- preclinical trial

study in which feasibility and safety data are collected prior to a medicinal product being trialed in humans. See also non-clinical study 
- principal investigator (PI)

person who is in overall charge of a clinical trial or research project

- privileged scaffold

structures with a partially defined conformation that possess many vectors for substitution, have the potential to produce a biologically active compound and are commonly preferred in established drugs

- process analytical technology (PAT)

system for designing, analyzing and controlling manufacturing processes through the evaluation of quality and performance indicators of raw and in-process materials and processes, with the aim of ensuring final product quality

- prodrug

medicinal product that is metabolized into a pharmacologically active substance following administration

- proof of concept

realization of a theory or method in order to demonstrate its viability

- property-based drug design

drug design approach where candidates are designed based on physicochemical properties, including the safety and absorption, distribution, metabolism and excretion profiles

\section{- protein binding}

degree to which medicinal products bind to large plasma proteins, which varies depending on the medicinal product chemistry and certain disease states, and determines how freely and efficiently a medicinal product can move into tissue or interact with receptors

\section{- protein expression}

synthesis, modification, regulation or manufacture of proteins in living organisms

\section{- protein therapy}

administration of functional proteins to a patient for the treatment of a disease or condition 
- protein-protein interactions (PPIs)

contact between two or more protein molecules through electrostatic forces and/or biochemical reactions

\section{- proteomics}

study of proteins and proteomes, including the techniques used to determine the entire set of proteins in an organism

\section{- protocol}

predefined document that details the objectives, design and implementation of an experiment, including a clinical trial

\section{- protocol amendment}

documentation of an intended change to the study plan after the study initiation date

\section{- protocol deviation}

documentation of an unintended departure from the study plan after the study initiation date

\section{- provenance}

record or knowledge of the source and history of materials utilized in research or manufacturing in order to ensure quality, and assess and manage the risk of contamination or infection

- purity

degree that a substance is free from contaminants or impurities. See also contamination

\section{- qualification}

clearance of equipment to function as intended by manufacturer specifications through examination and documented evidence, including examination of the installation, operation and performance of equipment. See also validation

\section{- qualified person (QP)}

individual with legal responsibility for certifying that a batch of medicinal product or material meets the set requirements prior to use in a clinical trial or release onto the market 


\section{Pharmaceutical Patent Analyst}

ISSN: 2046-8954

Frequency: 6 issues per year

Patent Analyst

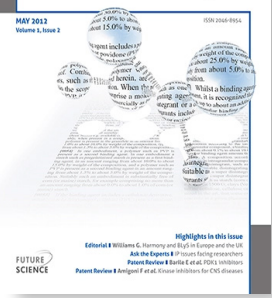

Pharmaceutical Patent Analyst

covers key areas such as:

- Chemical and biological entities of therapeutic significance

- Healthcare products (e.g., medical devices and drug-delivery systems)

- Drug-discovery and design technologies

- Inventions in related disciplines

(e.g., biotechnology and nanotechnology)

\section{Indexing}

- Chemical Abstracts - EMBASE/Excerpta Medica - EMCare - Emerging Sources Citation Index (Web of Science) - MEDLINE/Index Medicus - Research Alert - Scopus ${ }^{\circledR}$ 
- qualified person responsible for pharmacovigilance (QPPV) person with responsibility for ensuring the safety of human pharmaceutical products marketed by a company

- quality

suitability of a product for its intended purpose, based on the fulfilment of a set of predetermined requirements governed by a regulatory standard

- quality assurance

maintenance of a desired level of quality in medicinal products, done by ensuring that that the trial is performed and the data are generated, documented and reported in compliance with the applicable regulatory requirements. It may also refer to the independent quality unit required within good laboratory practice (GLP) for quality oversight

\section{- quality by design (QbD)}

process by which a product is developed using a strong understanding of the product and the risks involved to ensure the design, development and manufacture of medicinal produce is to the highest quality

- quality control (QC)

set of procedures undertaken within the quality management system to verify that operational activities and derived data meet manufacturer specifications through examination, supplied evidence and specific processes

\section{- quality control sample}

sample spiked with a known quantity of analyte in the same matrix as the unknown samples that can be used to assess the integrity, precision, reliability and validity of the results of unknown samples by monitoring the performance of the bioanalytical method. See also validation 
- quality system

system that provides document-based objective evidence to support the organizational processes, procedures, responsibilities and resources required to maintain and achieve the quality objectives during manufacture against regulatory requirements

- quantitative/real-time polymerase chain reaction (qPCR) technique to detect, characterize and quantify the amplified DNA produced by PCR by monitoring fluorescence levels from a reporter dye during the amplification process

\section{- quantitative structure-activity relationship (QSAR)}

mathematical parameters used to describe the relationship between a molecule's chemical structure and biological activity

\section{- raw data}

the original or primary data and documentations resulting from original observations, measurements and activities in a study, including laboratory worksheets, records, memoranda or notes, or exact copies of such, necessary for the reconstruction and evaluation of the report of that study

\section{- raw material}

unprocessed starting material that is used during the manufacture of, and is incorporated into, an active substance or intermediate

\section{- reactive metabolite}

drugs that have undergone biotransformation that results in a reactive species, which is often electrophilic and interferes with cellular function by reacting with nucleophilic groups of DNA and proteins to form a covalent bond

\section{- real-time release testing (RTRT)}

system that evaluates and ensures the quality of a medicinal product both during and following the manufacturing process based on product knowledge, process data and control 


\section{- reanalysis}

repetition of a series of analytical procedures from the processing steps on samples that have been previously analyzed

\section{- recall}

return or removal of a defective or possibly harmful marketed product after a relevant authority has deemed it to be in violation of their laws

\section{- receptor}

cellular macromolecule, or an assembly of macromolecules, that is concerned directly and specifically with chemical signaling between and within cells, and induces a cellular or tissue response upon binding a ligand

\section{- reference standard}

substance well characterized for its chemical and physical properties, accompanied by a certificate of analysis (CoA) that provides the purity and expiration (or retest) date

\section{- regulated bioanalysis}

bioanalytical processes that are conducted in compliance with regulatory requirements

\section{- regulatory validation}

conduct and reporting of experimental testing of a method to demonstrate that the concentration data are scientifically accurate, reproducible and reconstructable to allow valid decision-making for the intended purpose of the study and comply with regulated bioanalytical standards, as defined in guidance and guidelines

\section{- relative bioavailability}

bioavailability of a formulation of a drug compared with that of an alternative formulation

\section{- release criteria}

manufacturer-defined criteria against which a medicinal product is measured and evaluated to assess whether it is suitable for release 
- repeatability

precision of an experiment using the same sample under the same operating conditions over a short interval of time, in bioanalytical validation known as intraassay precision

- reproducibility

precision between multiple measurements of a sample or sample sets, which may include collaborative studies between laboratories or analysis at different times, and is often applied to the standardization of methodology

\section{- reverse transcription PCR (RT-PCR)}

method that allows RNA amplification that first involves the reverse transcription of RNA into complementary DNA (cDNA) by the enzyme reverse transcriptase, followed by PCR

\section{- reverse transcription qPCR (RT-qPCR)}

technique to detect, characterize and quantify the amplified RNA produced during reverse transcription PCR by monitoring fluorescence levels from a reporter dye

- risk

likelihood of occurrence of damage, loss or a negative outcome and its severity. See also risk analysis and risk management

\section{- risk analysis}

process of identifying and assessing the potential issues or hazards associated with a particular event, series of events or action

\section{- risk-based approach}

evaluation of the risk of failure versus the resource investment required to maintain the required quality level

\section{- risk management}

identification, assessment, control and avoidance of potential risk through defined policies, procedures and activities 


\section{- RNA interference (RNAi)}

process by which messenger RNA (mRNA) or siRNA molecules inhibit gene expression by directing enzymes to target mRNA and prevent translation

\section{- RNA sequencing (RNA-Seq)}

sequencing of RNA molecules to determine the primary sequence and relative abundance, generally through the use of next-generation sequencing (NGS) methods

\section{- safety}

protection and/or acceptance against control measures implemented to reduce risk to an acceptable level

\section{- safety follow-up}

continued collection and collation of data to gain knowledge of the safety of a medicinal product; which can include active surveillance, clinical trials, observational trials and passive surveillance

\section{- sample}

- in a lab: generic term encompassing calibrators, controls, blanks, unknowns and processed samples

- in clinical studies: a group of people, objects or items that are taken from a large population for measurement. The sample should be representative of the population to ensure that the findings can be generalized from research sample to a population as a whole

\section{- Sanger sequencing}

in vitro DNA sequencing technique whereby chain-terminating dideoxynucleotides (ddNTPs) are incorporated during DNA replication by DNA polymerase

\section{- scaffold}

fixed part of a molecule on which functional groups are substituted, deleted or exchanged

\section{- scale out (or scale horizontally)}

increase in the number of units to deliver an increase in production 
- scale up (or scale vertically)

increase in the size of the process to deliver an increase in production

- serious adverse event (SAE)

unexpected incident associated with the acquisition, testing, processing, storage and distribution of cells or tissues that, at any dose, could result in death or life-threatening, disabling or incapacitating illness, the transmission of communicable disease; or might result in, or prolong, hospitalization

\section{- serious adverse reaction (SAR)}

untoward reaction in a donor or recipient associated with the acquisition or application of cells or tissues that is fatal, lifethreatening, disabling or incapacitating, or might result in, or prolong, hospitalization

\section{- sham procedure}

control procedure that differs from the treatment or procedure under investigation by omitting a key therapeutic element

\section{- side effect}

any adverse consequence resulting from the use of a medicinal product

\section{- significance}

claim that a test result is unlikely to have occurred by chance but is instead likely to be attributable to specific cause, meaning the null hypothesis can be rejected. A common threshold for declaring statistical significance is a $p$-value of less than 0.05

\section{- single-cell analysis}

genomic, transcriptomic, proteomic or metabolomic study of a single cell

\section{- single-dose administration}

subsequent dose of the same drug is administered only after the drug of the previous dose or the drug completely eliminated from the body 


\section{- small molecule}

molecule with a low molecular weight (usually an atomic mass unit of $<900 \mathrm{Da}$ )

\section{- solubility}

propensity for an analyte to dissolve in a liquid forming a homogeneous solution, dependent on the physical and chemical properties of the solute and solvent

\section{- southern blot}

DNA sequencing technique whereby DNA fragments are separated on a gel by electrophoresis, followed by fragment detection by probe hybridization. See also DNA fragmentation

\section{- specification}

criteria used to determine whether a medicinal product, active substance or any intermediate is appropriate for its intended use

\section{specificity}

ability to measure the analyte unequivocally in the presence of other compounds, either exogenous or endogenous, in the matrix

\section{- specimen}

specifically selected portion of a material taken from a dynamic system and assumed to be representative of the parent material at the time it is taken

\section{- stability testing}

method to determine the change in concentration of a drug substance, intermediate or final product under a range of predetermined environmental factors over time

\section{- standard operating procedure (SOP)}

step-by-step written instructions to achieve efficiency, uniformity and quality output during complex routine procedures 


\section{- starting material}

raw material, intermediate or active substance used during the synthesis of an active substance, that is significantly integrated into the end product's structure

\section{- state of control}

maintenance of consistent performance and product quality through effective monitoring and control systems

\section{- steady state}

level of the drug in blood and tissue upon multiple dosing when input and output are at equilibrium during sequential dosing intervals

\section{- stem cell}

undifferentiated cell that is capable of differentiation into different cell types or dividing and multiplying to produce more of the same cell type. There are two main types of stem cells: embryonic stem cells that are formed during the blastocyst phase of embryological development and adult stem cells that are from adult tissue

\section{- structure-activity relationship (SAR)}

relationship between a molecule's chemical structure and its biological activity

\section{- structure-based drug design (SBDD)} process or method of designing a drug based on the 3D structure of the intended biological target alone or bound to an initial or optimized chemical entity

\section{- study director}

individual with overall responsibility for the technical conduct of the study, as well as for the interpretation, analysis, documentation and reporting of results, and represents the single point of study control

\section{- study monitor}

individual responsible for overseeing the progress of a clinical study and for ensuring that it is conducted, recorded and reported in accordance with the protocol, standard operating procedure (SOP), good clinical practice and applicable regulatory requirement(s) 
- study plan

document to describe the purpose and procedure of an experiment or a study

- study sample

group of subjects in a study, which can be selected randomly, by stratification or cluster sampling

- subject

clinical trial participant that receives either the medicinal product under investigation or a control

- supplemental new drug application (SNDA)

request to the US Food and Drug Administration (FDA) for permission to amend a drug product that already has an approved new drug application (NDA)

- target

biological molecule or process with which a drug (or compound) is assumed to interact

- target candidate

biological molecule or process with a strong therapeutic potential, for which the activity and specificity of chemical entities have been optimized

\section{- target validation}

process to identify and assess whether a molecular target is likely to have therapeutic benefit

\section{- telemetric monitoring}

monitoring method often used in preclinical testing to assess cardiovascular safety, which allows heart rhythm and QRS pattern to be monitored whilst the subject under study can move freely 


\section{- the three Rs}

guidelines for the use of animals in an experiment, which call on researchers to replace animal testing with other methods where possible, reduce the number of animals needed as much as possible and refine methods so that they cause minimal pain, suffering and distress

\section{- therapeutic immunosuppression}

intentional suppression of the body's natural immune response by drugs or radiation to prevent transplant or graft rejection and manage autoimmune diseases

\section{- therapy}

treatment intended to cure or manage symptoms of a disease, illness or injury

- three-dimensional quantitative structure-activity relationship (3D-QSAR)

extension of the structure-activity relationship that considers the 3D properties of the ligands to predict their biological activities using statistical analysis

\section{- total drug}

study of adverse effects of substances or agents on living organisms, which is a critical aspect of the drug discovery process included in the ADMET concept

\section{- toxicity}

ability of a compound to cause harm to an organism

\section{- toxicology}

study of adverse effects of substances or agents on living organisms. A critical aspect of the drug discovery process included in the ADMET concept 


\section{- translation}

- clinical translation: development and integration of knowledge gained from preclinical scientific research into practical applications such as testing and/or use in humans for the prevention, diagnosis and treatment of disease

- genetics: stage of gene expression in which amino acid chains and subsequently proteins are synthesized by ribosomes from messenger RNA (mRNA) and reliably fulfils its intended purpose, quality attributes and characteristics

\section{- unexpected adverse reaction (UAR)}

adverse reaction where the nature, severity or outcome is not consistent with applicable product information or characteristics

\section{- upstream processing}

initial stages of bioprocessing in which the product, such as a cell line, is grown

- user requirement brief (URB)

document detailing an end user's expectations for the outcome of an entire project

\section{- user requirement specification (URS)}

document detailing an end user's expectations for the outcome of an individual component of a project

\section{- validation}

process of gathering evidence in order to establish whether a process, standard operating procedure (SOP), piece of equipment or environment is suitable to produce a product that consistently and reliably fulfils its intended purpose, quality attributes and characteristicsproject

- $V_{\max }$

value that describes the maximum rate of reaction 
- western blot

analytical technique used to detect specific proteins, through the specificity of the antibody-antigen interaction, in a sample of tissue homogenate or extract separated based on molecular characteristics

- whole bioprocessing

complete process from biopsy to clinical administration of a cell therapy product to a patient

- Z' factor

measure of statistical effect size, used to determine whether an assay response is large enough to warrant further attention 


\section{EQUATIONS}

\section{\%accuracy}

$\%$ accuracy $=($ determined value $/$ true value $) \times 100$

\section{\%bias}

$$
\% \text { bias }=\frac{\text { mean measured conc. }- \text { nominal conc. }}{\text { nominal conc. }} \times 100
$$

\section{$\% \mathrm{CV}$}

$$
\% \mathrm{CV}=\frac{\text { standard deviation }(\mathrm{SD})}{\text { mean measured conc. }} \times 100
$$

\section{\%recovery}

$$
\% \text { recovery }=100 \times \text { mean }\left(\frac{\text { peak area ratio }(\text { extracted samples })}{\text { peak area ratio }(\text { post-extraction spiked samples })}\right)
$$

Note: a ratio of means is different from a mean of ratios

\section{bioavailability}

$\frac{\text { AUC (administration via way } \mathrm{X})}{\text { AUC (intravenous administration) }}$

Where:

AUC typically refers to plasma AUC.

AUC-intravascular refers to the plasma AUC obtained after intravenous drug administration as opposed to AUC-extravascular, which refers to the plasma AUC obtained after administration by a route other than intravenous administration. 


\section{fraction unbound (Fu)}

$\mathrm{Fu}=1-\mathrm{Fb}=1-\mathrm{Cb} / \mathrm{Ctot}=1-\mathrm{Cb} /(\mathrm{Cb}+\mathrm{Cu})$

Where:

$\mathrm{Cb}=$ bound compound concentration = compound concentration in plasma after, e.g., equilibrium dialysis

Ctot $=$ total concentration of compound in plasma

$\mathrm{Cu}=$ free compound concentration in plasma; if having performed equilibrium dialysis, this is the compound concentration in the protein free dialysate

IS $=$ mean of $\frac{\text { peak area ratio in presence of matrix }}{\text { peak area ratio in absence of matrix }}$

Note: a ratio of means is different from a mean of ratios.

\section{mass accuracy}

In ppm, is the degree of closeness of the measured $m / z$ value to the actual $\mathrm{m} / \mathrm{z}$ value. Calculated by mass error/actual mass-to-charge $\times 10^{6}$, where

$\frac{(\text { measured mass - actual mass })}{(\text { actual mass })} \times 10^{6}$

mass error is the measured $\mathrm{m} / \mathrm{z}$ value - actual $\mathrm{m} / \mathrm{z}$ value.

\section{matrix factor (MF)}

The ratio of the analyte response in the presence of matrix to the response in the absence of matrix.

$$
\mathrm{MF}=\frac{\text { analyte response in the presence of matrix }}{\text { analyte response in the absence of matrix }}
$$




\section{theoretical plates}

$\mathrm{N}$, the number of theoretical plates, is one index used to determine the kinetic performance of chromatographic columns, pertaining specifically to the minimization of peak broadening. It may be calculated using the following equation for Gaussian peak:

$\mathrm{N}=16\left(\frac{\mathrm{tr}}{\mathrm{W}}\right)^{2}$

Where:

$\mathrm{tr}=$ retention time;

$W=$ peak width at base.

\section{van Deemter equation}

The van Deemter equation relates the theoretical plate height, or efficiency, of a chromatographic column to the various flow and kinetic parameters which cause peak broadening, as follows:

$\mathrm{HETP}=\mathrm{A}+\frac{\mathrm{B}}{u}+\mathrm{C} \cdot u$

Where:

HETP = height equivalent to a theoretical plate, a measure of the dispersion value of the column [m];

$A=$ Eddy-diffusion parameter, related to channeling through a nonideal packing [m];

$\mathrm{B}=$ diffusion coefficient of the eluting particles in the longitudinal direction, resulting in dispersion $\left[\mathrm{m}^{2} \mathrm{~s}^{-1}\right]$;

$C=$ resistance to mass transfer coefficient of the analyte between mobile and stationary phase [s];

$\mathrm{u}=$ linear velocity $\left[\mathrm{m} \mathrm{s}^{-1}\right]$. 


\section{(C) Frontage \\ YOUR R RU D DEVELOPMENT PARTNER}

\section{Frontage Laboratories, Inc. Your Drug Development Partner}

Frontage Laboratories, Inc. is a contract research organization (CRO) that provides integrated, scientifically-driven, product development services throughout the drug discovery and development process to enable pharmaceutical and biotechnology companies to achieve their development goals.

Comprehensive services include drug metabolism and pharmacokinetics, analytical testing and formulation development, preclinical and clinical trial material manufacturing, bioanalysis, preclinical safety and toxicology assessment and early phase clinical studies.

Rigorous scientific expertise, high quality standards and regulatory compliance is committed to every program. Frontage has enabled many innovator, generic and consumer health companies of all sizes to advance hundreds of molecules through development and file regulatory submissions in global markets allowing for successful development of important therapies and products for patients worldwide.

Integrated:

Capability and expertise to solve complex problems
Expertise:

Deep pool of talented \& highly-qualified scientists

\section{Quality:}

Strong track of record of regulatory inspections

\section{Contact Us:}

Tel: 610-232-0100

Address: 700 Pennsylvania Drive, Exton, PA 19341. USA

Email: sales@frontagelab.com

Website: www.frontagelab.com 


\section{RxNET AIMS AND SCOPE}

RxNet is a free online community, uniting scientists from the fields of chemistry, biochemistry and beyond to further the ever-booming industry of drug discovery and development.

On RxNet, in partnership with our associated journals, Future Drug Discovery, Future Medicinal Chemistry, Pharmaceutical Patent Analyst and Therapeutic Delivery, we aim to provide current and exciting research and information on all aspects of the drug discovery pipeline. This includes: novel small molecules,

\section{Expert Panel}

The RxNet Advisory Expert Panel is drawn from the leading forces in medicinal chemistry and drug discovery:

\footnotetext{
Abad-Zapatero, Cele Univ. Illinois at Chicago, IL, USA Andrade, Carolina Federal University of Goias, Brazil Atanasov, Atanas University of Vienna, Austria Barjorath, Jürgen University of Bonn, Germany Benchekroun, Mohamed Sussex University, UK Bernstein, Peter PhaRmaB LLC, PA, USA

Brown, Nathan BenevolentAl, London, UK Caron, Giulia University of Turin, Italy

Chaguturu, Rathnam SRI International, CA, USA
}

biopharmaceuticals, vaccine development, industry updates and preclinical and phase I studies - from lead to license. We do this by publishing the latest news and up-to-date research from the field, as well as expert interviews and opinion, peer-reviewed journal articles and exclusive multimedia content.

RxNet members can connect and collaborate with industry leaders and academic experts as well as share their own research and opinion, as 'community posts' without the wait.

\section{FUTURE DRUG DISCOVERY AIMS \& SCOPE}

Future Drug Discovery is a peer-reviewed journal covering the latest breakthrough science in drug discovery, research and development. The journal strives to drive drug discovery by taking a multi-disciplinary and forward-looking stance, presenting new advances and discussing their applications and translation. Future Drug Discovery is also a forum for discussing the field at large.

The journal embraces the importance of publishing all good-quality research with the potential to further the progress of research in these fields. All original research articles are considered that are within the journal's scope, and have been conducted with scientific rigor and research integrity. The journal also features review articles, editorials and perspectives, providing readers with a leading source of commentary and analysis.

The journal publishes original research covering the entire drug discovery pipeline, plus topics of interest to the drug discovery community, including:

- Biopharmaceuticals \& large molecules including biologics, biosimilars, vaccines, etc

- Biotechnology

- Computational chemistry \& informatics

- Diagnostic approaches

- Drug regulation \& market analysis

- Drug repurposing

- Drug targeting \& delivery

- High-throughput screening \& assay development

- Hit-to-lead \& lead optimization
Devita, Robert Mount Sinai Hospital, NY, USA Greene, William MedChem Discovery Consulting, NJ, USA Hurley, Chris Charles River, Chelmsford, UK Honey, Mark Sussex University, UK

Komatani, Takeshi Shusaku•Yamamoto, Osaka, Japan Lushington, Gerald Lushington in Silico Consulting, KS, USA

Lindsley, Craig University of Vanderlbilt, TN, USA Laufer, Stefan University of Tübingen, Germany Malemud, Charles Case Western Reserve University School of Medicine, OH, USA

Nixon, Gemma University of Liverpool, UK

Price, David Pfizer, MA, USA

Steadman, Vicky Selcia, Essex, UK

Zablocki, Jedd Gilead Sciences, CA, USA
- IP \& pharmacoeconomics

- Natural products

- Omics technologies

- Pharmacokinetics \& toxicology

- Preclinical \& early phase clinical studies

- Rational drug design

- Small molecules \& medicinal chemistry

- Structural biology \& biophysics

- Target discovery \& validation

- Open science in drug discovery

\section{Editorial Board}

Caron, Giulia University of Torino, Italy Clark, David Charles River Laboratories, Harlow, UK Jacoby, Edgar Janssen, Beerse, Belgium Jones, Neil Cancer Research UK, Cambridge, UK Morris, Dave C Univ. North Carolina at Chapel Hill, NC, USA

Panyam, Jayanth University of Minnesota, MI, USA Rees, Steve AstraZeneca, Cambridge, UK

Reynisson, Johannes Keele University, Newcastle, UK Schopfer, Ulrich Novartis Pharma AG, Basel, Switzerland

Trippier, Paul Texas Tech University Health Sciences Center, TX, USA

Williams, Rob Cancer Research UK, London, UK

Wilson, Francis Summit Therapeutics, Abingdon, UK Zhang, Xingcai Harvard University, MA, USA 
For all print-only, online-only or print \& online subscription queries, please contact us at subscriptions@future-science.com

\section{Ordering Information}

Please contact your local sales representative to place an order:

\section{Worldwide}

Future Science Ltd

Unitec House, 2 Albert Place,

London, N3 10B, UK

Tel.: +44 (0)20 83716090

Fax: +44 (0)20 83432313

subscriptions@future-science.com

\section{Turkey}

Gemini

Tel.: +90 2164643300 - 04

bilgi@geminiltd.com.tr

\section{Republic of Korea}

Exclusive sales agent:

Tel.: +821032963611

seonghwi@accucoms.com

\section{Japan}

USACO Corporation

Tel.: +81-3-3505-3257

Fax: +81-3-3505-6283

import@usaco.co.jp

\section{Hong Kong, Taiwan and Macau}

FlySheet Information Services Co. Ltd.

Tel.: 886-2-26581258

emedical@flysheet.com.tw

\section{Latin America and the Caribbean}

dotLib

Tel.: +55 (21) 34313430

Contact: Diego Gutierrez

diego.gutierrez@dotlib.com

\section{Israel}

Probook

Contact: liana Abend David

llana@probook.co.il

\section{Advertising in RxNet and Future Drug Discovery}

We offer a range of online advertising options with attractive introductory rates and package deals available. If you would like to know more about advertising on RxNet and Future Drug Discovery or require a quotation, please contact Dionne Murray: d.murray@future-science-group. com.

\section{Open access}

Future Drug Discovery is an open access journal, under a CC-BY-NC-ND license. For more information on the license type used and the rights granted by that license, please visit www.future-science.com/authorguide.

\section{Reprints}

Article reprints are available through our reprint service. Please contact Sam Cavana: s.cavana@future-science.com.

\section{Consortia pricing}

Future Drug Discovery welcomes discussion with all consortia, and offers flexible packages and discounted prices. If you have specific questions or would like a quote please contact info@future-science.com for more details. 


\title{
FUTURE DRUG DISCOVERY AUTHOR GUIDELINES
}

\author{
Our complete Author Guidelines are available at: https://www.future-science.com/journal/fdd
}

\begin{abstract}
Audience
The audience for Future Drug Discovery comprises research scientists, decision-makers and other professionals from across drug discovery, R\&D. The journal will act as a valuable reference for all those whose research interests lie in the discovery and development of therapeutics.
\end{abstract}

\section{Submission}

We accept unsolicited manuscripts. If you are interested in submitting an article, or have any queries regarding article submission, please contact the Editorial Director directly (I.dormer@future-science.com). For new article proposals, the Editorial Director will require a brief article outline and working title in the first instance. We also have an active commissioning program whereby the Editor, under the advice of the Editorial Advisory Panel, solicits articles directly for publication.

\section{Peer review \& revision}

Once the manuscript has been received in-house, it will undergo initial internal review by the Journal Editor. Articles deemed suitable for consideration will then proceed to external peer review (dependent on article type - for more details, see the section on External peer review below). This usually takes around 4 weeks, although an Accelerated Publication option is also available. Please provide a list of suitable peer reviewers with your initial submission.

\section{In-house production}

Accepted manuscripts will undergo production in-house. This will involve type-setting, copy-editing, proof-reading and re-drawing of any graphics. Authors will receive proofs of their article for approval and sign off.

\section{Article types}

For a more detailed description of each article type, please view our author guidelines at: www.future-science.com Please not that word limits quoted below for each article type exclude the abstract, summary points, references and figure/table legends, as appropriate.

\section{Reviews}

\section{Word limit: 8000}

Reviews aim to highlight recent significant advances in research, ongoing challenges and unmet needs; authors should be concise and critical in their appraisal of the subject matter, and strive for clarity. The focus should be on key, defining developments rather than providing a comprehensive literature survey. Reviews should provide balanced coverage of the field and not focus predominantly on the author's own research. Authors are encouraged to include their own perspective on current trends and future directions, particularly in the 'Future perspective' section. Review articles undergo external peer review.

\section{Systematic Reviews}

\section{Word limit: 6000}

Systematic reviews should be conducted following the recommendations of PRISMA (http://www.prisma-statement.org).

\section{Perspectives}

Word limit: 8000

Perspectives have the same basic structure and length as review articles; however, they should be more speculative and forward-looking, even visionary. They offer the author the opportunity to present criticism, address controversy or provide a personal angle on a significant issue. Authors of perspectives are encouraged to be opinionated, with all positions concisely and clearly argued and referenced. Referees will be briefed to review these articles for quality and relevance of argument only. They will not necessarily be expected to agree with the author's position.

\section{Editorials}

Word limit: 1500

Editorials are short articles that provide an insight into, or snapshot of issues of topical importance to the journal's target audience or researchers and other professionals. The intention is that the article should offer an expert perspective on a topic of recent interest. More detailed discussions can take the form of Commentary articles. Invited Editorial articles undergo internal review; unsolicited Editorials will undergo external peer review at the Editor's discretion.

\section{Commentaries}

\section{Word limit: 3000}

Commentaries are short articles that are similar to Editorials, yet provide a more detailed discussion of a topic. Invited Commentary articles undergo internal review; unsolicited Commentaries will undergo external peer review at the Editor's discretion.

\section{Conference Reports \\ Word limit: 3000}

Conference reports aim to summarize the most important research presented at a recent relevant meeting or event. It is not usually feasible to attempt comprehensive coverage of the conference; authors should therefore focus on those presentations that are most topical, interesting or thought provoking. Reports should be submitted within 6 weeks of the end of the conference.

\section{Company/Institutional Profiles \\ Word limit: 2000}

Company or Institutional profiles allow representatives from the body to describe the work currently being carried out within their particular organization, relevant to the field of the journal in question. These reports are intended to provide an insight into the history and strategy of the body. Individuals are invited to write a Company or Institutional Profiles at the Editor's discretion, and the contents of the piece undergo internal review.

\section{Original Research Articles}

The following types of research article are accepted, all of which undergo peer review:

\section{Primary Research Article}

Word limit: 8000

Research articles should present methodologically accurate work that has potential to be applied to the drug discovery 
process. Research should be reported succinctly; the inclusion of detailed background discussion is to be avoided. Supporting data or further experimental details can be submitted as Supplementary Information. If requested by the Editor or reviewers, authors should be able to provide additional relevant original data underpinning their research.

\section{Preliminary Communication}

Word limit: 5000 words

Preliminary communication articles are intended for short reports of studies that present promising improvements or developments on existing areas of research.

\section{Methodology}

Word limit: 5000 words

Methodology articles should provide an overview of a new experimental or computational method, test or procedure. The method described may be either completely novel, or may offer a demonstrable improvement on an existing method.

\section{Study Protocol and Trial Design Articles}

Word limit: 5000 words

Study protocols or trial design articles can cover proposed or ongoing research. For protocols of registered trials, the last line of the abstract should include the trial registry and the unique identifying number.

\section{Short Communication}

\section{Word limit: 5000 words}

Short communications are short reports of studies presenting a small improvement on a current method/technique, additional results gleaned from other research studies, or experiments where no conclusion was reached or the results were negative.

\section{Manuscript preparation}

\section{Spacing \& headings}

Please use double line spacing throughout the manuscript. No more than four levels of subheading should be used to divide the text and should be clearly designated.

\section{Abbreviations}

Abbreviations should be defined on their first appearance, and in any table and figure footnotes.

\section{Spelling}

US-preferred spelling will be used in the final publication.

\section{Copyright}

If a figure, table or box has been published previously (even if you were the author), acknowledge the original source and submit written permission from the copyright holder to reproduce the material where necessary. As the author of your manuscript, you are responsible for obtaining permissions to use material owned by others. Since the permission-seeking process can be remarkably time-consuming. it is wise to begin writing for permission as soon as possible. Please send us photocopies of letters or forms granting you permission for the use of copyrighted material so that we can see that any special requirements with regard to wording and placement of credits are fulfilled. Keep the originals for your files. If payment is required for use of the figure, this should be covered by the author.

\section{Key formatting points}

Please ensure your paper concurs with the following article format:

Title: concise, not more than 120 characters.

Author(s) names \& affiliations: including full name, address, phone \& fax numbers and e-mail.

Abstract/Summary: approximately 120 words. No references should be cited in the abstract.

Keywords: approximately 5-10 keywords for the review, including brief definitions.

Body of the article: article content under relevant headings and subheadings.

Conclusion: analysis of the data presented in the review.

Future perspective: a speculative viewpoint on how the field will evolve in 5-10 years time.

Executive summary: bulleted summary points that illustrate the main topics or conclusions made under each of the main headings of the article.

References:

- Primary literature references, and any patents or websites, should be numerically listed in the reference section in the order that they occur in the text.

- Should appear as a number i.e., [1,2] in the text.

- Any references that are cited in figures/tables/boxes that do not appear in the text should also be numerically listed in the reference section in the order that they occur in the text.

- If there are 1-6 authors, list all authors' names. If there are more than 6 authors, list the first 3 authors only, followed by 'et al'.

- The Newlands Press Endnote style can be downloaded from: www.future-science.com/page/authors.jsp

Reference annotations: please highlight 6-8 references that are of particular significance to the subject and provide a brief (1-2 line) synopsis. Papers should be highlighted as one of the following:

$\mathrm{n}$ of interest; $\mathrm{nn}$ of considerable interest

Figures/Tables/Boxes: Summary figures/tables/boxes are very useful, and we encourage their use in reviews/perspectives/special reports. The author should include illustrations and tables to condense and illustrate the information they wish to convey. Commentary that augments an article and could be viewed as 'stand-alone' should be included in a separate box. An example would be a summary of a particular trial or trial series, a case study summary or a series of terms explained. Please include scale bars where appropriate.

If any of the figures or tables used in the manuscript requires permission from the original publisher, it is the author's responsibility to obtain this. Figures must be in an editable format. 


\section{FUTURE DRUG DISCOVERY JOURNAL POLICIES}

Newlands Press titles endorse the Recommendations for the Conduct, Reporting, Editing and Publication of Scholarly Work in Medical Journals, issued by the International Committee for Medical Journal Editors, and the Code of Conduct and Best Practice Guidelines for Journal Editors, produced by the Committee on Publication Ethics, and GPP3.This information is also available at www.future-science.com.

\section{Manuscript submission \& processing}

Newlands Press titles publish a range of article types, including solicited and unsolicited reviews, perspectives and original research articles. Receipt of all manuscripts will be acknowledged within I week and authors will be notified as to whether the article is to progress to external review. Initial screening of articles by internal editorial staff will assess the topicality and importance of the subject, the clarity of presentation, and relevance to the audience of the journal in question. If you are interested in submitting an article, or have any queries regarding article submission, please contact the Editorial Director (contact information can be found on our website at: www.future-science.com). For new article proposals, the Editorial Director will require a brief article outline and working title in the first instance. We also have an active commissioning program whereby the Commissioning Editor, under the advice of the Editorial Board, solicits articles directly for publication. External peer review: Through a rigorous peer-review process, Newlands Press titles aim to ensure that reviews are unbiased, scientifically accurate and clinically relevant. All articles are peer reviewed by three or more members of the International Editorial Board or other specialists selected on the basis of experience and expertise. Review is performed on a double-blind basis - the identities of peer reviewers and authors are kept confidential. Peer reviewers must disclose potential conflicts of interests that may affect their ability to provide an unbiased appraisal (see Conflict of Interest Policy below). Peer reviewers provide general comments to the editor and both general and specific comments to the author(s).

Where an author believes that an editor has made an error in declining a paper, they may submit an appeal. The appeal letter should clearly state the reasons why the author(s) considers the decision to be incorrect and provide detailed, specific responses to any comments relating to the rejection of the review. Further advice from members of the journal's Editorial Board and/or other external experts will be sought regarding eligibility for re-review.

Revision: Most manuscripts require some degree of revision prior to acceptance.Authors should provide two copies of the revised manuscript - one of which should be highlighted to show where changes have been made. Detailed responses to reviewers' comments, in a covering letter/email, are also required. Manuscripts may be accepted at this point or may be subject to further peer review. The final decision on acceptability for publication lies with the journal editor.

\section{Post-acceptance}

Accepted manuscripts will undergo production in-house. This will involve type-setting, copy-editing, proof-reading and re-drawing of any graphics.Authors will receive proofs of their article for approval and sign off and will be asked to sign a transfer of copyright agreement, except in circumstances where the author is ineligible to do so (e.g., government employees in some countries).

\section{Embargo policy}

Following the acceptance of articles for publication, authors (and their institutions, etc.) are welcome to publicize the publication; authors wishing to do so, should advise the editor of the details beforehand. No publicity relating to publication in a Newlands Press journal should be carried out while the manuscript is under consideration. However, prior publicity linked to presentations at meetings does not jeopardize publication in a Newlands Press journal. In cases where data may be of overwhelming public health importance, the above policy may be waived; should this be the case, the appropriate authorities responsible for public health should decide whether to disseminate information to physicians and the media in advance and should be responsible for this decision. The journal editor should be informed if these circumstances apply. Any queries relating to publicity of manuscripts should be directed to the journal editor.

\section{Disclosure \& conflict of interest policy}

Authors must state explicitly whether financial and/or nonfinancial relationships exist that potentially conflict with the subject matter or materials discussed in the manuscript and any such potential conflict of interest (including sources of funding) should be summarized in a separate section of the published article. Authors must disclose whether they have received writing assistance and identify the sources of funding for such assistance. Authors declaring no conflict of interest are required to publish a statement to that effect within the article.

Authors must certify that they have disclosed relationships in which they (or a close family member): is employed, is a contractor, provides services, or has otherwise collaborated in commercial or scientific pursuits - even in the absence of direct monetary remuneration. Stock holdings and issued or pending patents of an author or family member should also be disclosed. This is list is not exclusive of other forms of financial involvement.A 36-month disclosure window should be used. Details of relevant conflicts of interests (or the lack of) must be declared in the 'Disclosure' section of the manuscript for all listed authors.

External peer reviewers must disclose any conflicts of interest that could bias their opinions of the manuscript, and they should disqualify themselves from reviewing specific manuscripts if they believe it appropriate. Should any such conflict of interest be declared, the journal editor will judge whether the reviewer's comments should be recognized or will interpret the reviewer's comments in the context of any such declaration.

\section{Ethical conduct of research}

For studies involving data relating to human or animal experimental investigations, appropriate institutional review board approval is required and should be described within the article. For those investigators who do not have formal ethics review committees, the principles outlined in the Declaration of Helsinki should be followed. For investigations involving human subjects, authors should explain how informed consent was obtained from the participants involved. 


\section{Patients' rights to privacy}

Patients have a right to privacy that should not be infringed without informed consent. Identifying information should not be included unless the information is essential for scientific purposes and the patient (or parent or legal guardian) gives written informed consent for publication. Informed consent for this purpose requires that the patient be shown the manuscript to be published. When informed consent has been obtained it should be indicated in the manuscript.

In attempting to maintain patient anonymity, identifying details should be omitted where they are not essential. However, patient data should never be amended or falsified. Informed consent should be obtained whenever there is any doubt that anonymity can be assured.

\section{Use of personal communications \& unpublished data}

Where an individual is identified within a review as a source of information in a personal communication or as a source for unpublished data, authors should include a signed statement of permission from the individual(s) concerned and specify the date of communication.

\section{Clinical trial registration}

Newlands Press titles prefer to publish clinical trials that have been included in a clinical trials registry that is accessible to the public at no charge, is electronically searchable, is open to prospective registrants and is managed by a not-for-profit organization, such as www.clinicaltrials.gov (sponsored by the United States National Library of Medicine). Where a clinical trial registration number is available, this should be included at the end of the abstract and also listed the first time the authors use a trial acronym to refer to the trial they are reporting in the manuscript. Unregistered clinical trials should be declared as such, and the reason for nonregistration should be provided. Whilst referees will take registration status into account, all well designed and presented trials and corresponding data will be considered for publication.

\section{Errata/corrigenda}

Mistakes by either editor or author should be identified wherever possible and an erratum or corrigendum published at the earliest opportunity. We will attempt to contact the author of the original article to confirm any error, and publish an appropriate erratum or corrigendum at the earliest opportunity.

\section{Duplicate publication/submission \& plagiarism}

All manuscripts submitted to Newlands Press titles are considered for publication on the understanding that they have not been published previously elsewhere or are under consideration for publication elsewhere. The journal may, however, consider republication of a paper previously published in a language other than English, subject to prominent disclosure of the original source and with any necessary permission. Authors will be asked to certify that the manuscript represents valid work and that neither this manuscript nor one with substantially similar content under their authorship has been published or is being considered for publication elsewhere. Where specific findings from a particular study have been previously published (in Newlands Press titles or elsewhere), Newlands Press titles will not consider manuscripts reporting the same findings, except where: the results are substantially reanalyzed, reinterpreted for a different audience, or translated into another language; the primary publication is clearly acknowledged and cited and the trial registration number(where available) of the original research is included; and the publication is clearly presented as an analysis derived from the primary publication results or marked as a translation, with appropriate permission obtained from the previous publisher and copyright laws upheld. All submitted articles will be evaluated using plagiarism detection software, which compares the submitted manuscript with full text articles from all major journals databases and the internet. The use of published or unpublished ideas, words or other intellectual property derived from other sources without attribution or permission, and representation of such as those of the author(s) is regarded as scientific misconduct and will be addressed as such.

\section{Scientific misconduct \& retraction}

If misconduct by authors or reviewers is suspected, either pre- or post-publication, action will be taken. An explanation will be sought from the party or parties considered to be involved. If the response is unsatisfactory, then an appropriate authority will be asked to investigate fully. Newlands Press will make all reasonable attempts to obtain a resolution in any such eventuality and correct the record or archive as necessary (publishing a retraction of the article as required).

\section{Compliance with funder open or public access policies}

Newlands Press is supportive of open and public access policies mandated by various funding bodies. In the first instance, please check whether your article type is covered by your funder mandate (i.e., in some cases, funder policies only cover research articles, rather than review articles). Please advise the Editor on submission if your article was funded by any of the bodies below. Where open access publication is a requirement of your funding, our article processing charge will need to be paid (in many cases, this will be covered by your funder, and you should check the specific details of this on the funder website). As standard for our Open Access option, articles are published under a CC BY-NC-ND license, and this will be used in the first instance; however, where the funder requires it, articles can be published under a difference Creative Commons license (i.e., the CC BY license in the case of The Wellcome Trust).

\section{Self-archive policy}

Newlands Press is supportive of self-archiving. Should you be interested in archiving your work, please be aware of the policies outlined on our website at: www.future-science.com/page/authors.jsp. 


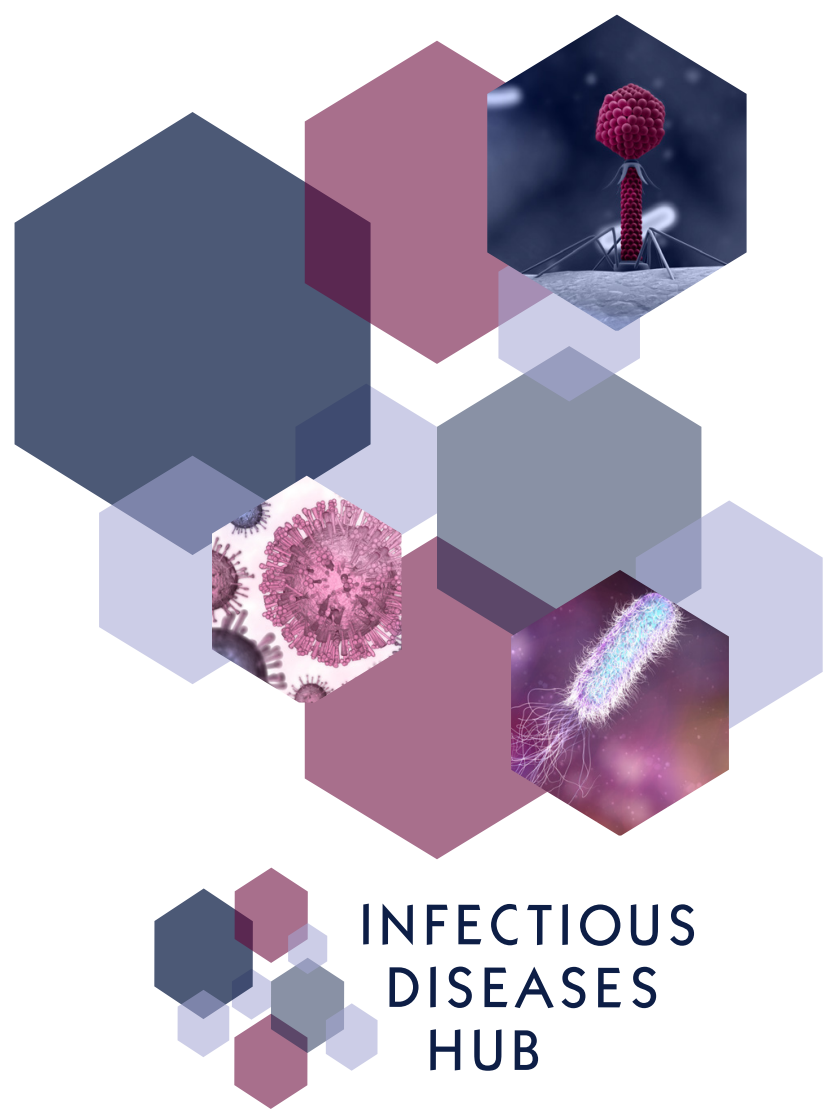

\section{The home of infectious disease information and research}

Infectious Diseases Hub aims to provide up-to-date, essential research and information on all aspects of microbiology, virology, mycology and parasitology - from bench to bedside.

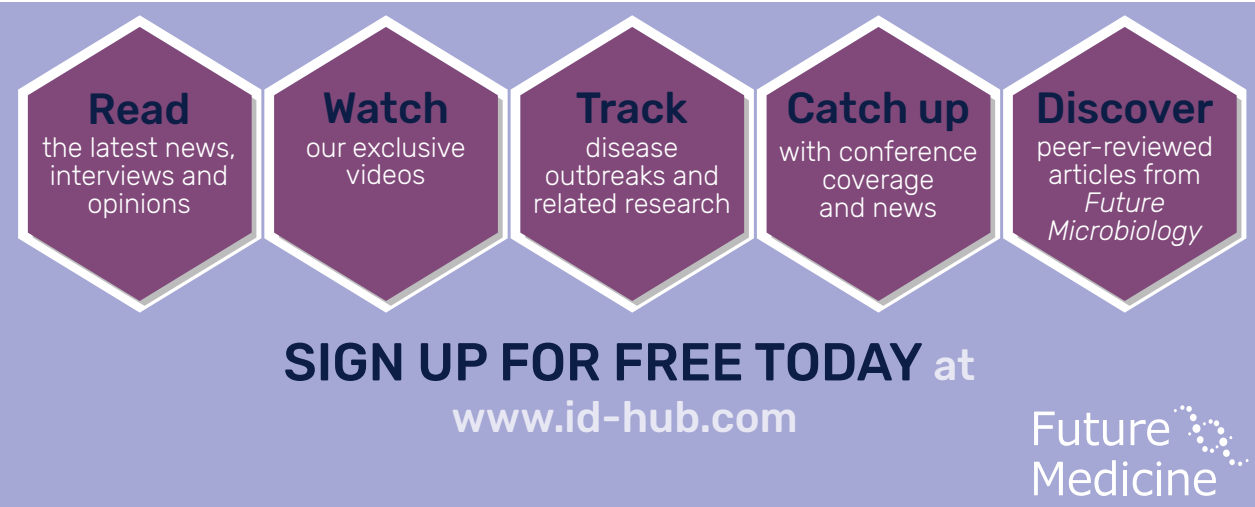




\section{INDEX}

abbreviated new drug application (ANDA), 6 absolute bioavailability, 6

absorption, 6

accelerator mass spectrometry, 6

active substance, 6

adjuvant, 6

advanced therapy medicinal product (ATMP), 6

ADME, 7

adventitious agent, 7

affinity, 7

affinity-based biosensor, 7

agonist, 7

allosteric binding site, 7

analog, 7

analyte, 7

ancillary material, 8

antagonist, 8

antibody, 8

AtlasCBS (chemico-biological-space)

server, 8

antibody-drug conjugate (ADC), 8

antidrug antibody (ADA), 8

antigen, 8

aptamer, 8

assay, 10

audit, 10

batch, 10

beyond rule of five compounds, 10

bioactive agent, 10

bioactivity, 10

bioassay, 10

bioavailability, 11

bioburden, 11

biocompatibility, 11

biodistribution, 11

bioequivalence, 11

bioinformatics, 11

biologic, 11 biological agent, 11

biological medicinal product, 11

biological substance, 12

biologics license application (BLA), 12

biomarker, 12

biomolecule, 12

biopharmaceuticals, 12

bioprocess development, 12

bioprocessing, 12

biosimilar, 13

biostatistics, 13

biotransformation, 13

bispecific, 13

breakthrough therapy, 13

capsid, 13

cell therapy, 13

cell-based neutralizing antibody assay, 15

centralized authorization procedure, 15

chemistry, manufacturing and control (CMC)

section, 15

chemoinformatics, 15

chief investigator, 15

cleanroom (or clean facility), 15

clinical benefit, 15

clinical equivalent, 16

clinical hold, 16

clinical investigator, 16

clinical laboratory improvement

amendments (CLIA), 16

clinical outcome, 16

clinical research organization (CRO), 16

clinical sample, 16

clinical trial, 17

clinical trial authorization, 17

clinical validation, 17

closed system, 17

co-administered medicines, 17

combination cell therapy, 17

combination product, 17

combination therapy, 18 
combined advanced therapy medicinal

product (combined ATMP), 18

comedication stability, 18

comparability, 18

comparable, 18

competent authority, 18

compound library, 19

computer-aided (or-assisted) drug design

(CADD), 19

conformational analysis, 19

confounding factor, 19

contained use, 19

contaminant, 19

contamination, 19

continued process verification, 20

contract development and manufacturing

organization (CDMO), 20

contract manufacturing organization (CMO), 20

contract research organization (CRO), 20

control (subject/group), 20

cost of goods sold (COGS), 20

cost-benefit analysis, 22

CRISPR/Cas9, 22

cross-contamination, 22

cytotherapy, 22

cytotoxicity, 22

de novo design, 22

disease-in-a-dish, 22

distribution, 22

DNA construct, 22

DNA extraction/isolation, 23

DNA fingerprinting, 23

DNA fragmentation, 23

DNA methylation, 23

DNA polymerase, 23

DNA profiling, 23

DNA short tandem repeat profiling (DNA STR profiling), 23

dosage regimen, 23

dose, 23 dose-response curve, 24

dosing interval, 24

dosing vehicle, 24

downstream processing, 24

drug, 24

drug master file, 24

drug metabolism, 25

drug-drug interaction, 25

druggable, 25

eastern blot, 25

efficacy follow-up, 25

elimination half-life, 25

end point, 25

enzyme, 25

enzyme induction, 25

enzyme inhibition, 26

ethics committee, 26

European Medicines Agency (EMA), 26

excipient, 26

excretion, 26

ex vivo, 26

false negative, 26

false positive, 26

first-in-class, 26

first-pass effect, 27

flow cytometry, 27

fluorescence activated cell sorting

(FACS), 27

fluorescence imaging, 27

fluorescent in situ hybridization (FISH), 27

fluorophore, 27

Food and Drug Administration (FDA), 27

formulation, 27

Förster resonance energy transfer (FRET), 28 fragment-based drug design, 28

free drug, 28

gene editing, 28

gene expression, 28

gene expression profiling, 29

gene therapy, 29 
generic, 29

generic drug, 29

genetic engineering, 29

genetic locus, 29

genetic mapping, 29

genetic marker, 29

genome, 29

genome library, 29

genomic modification, 30

genotype, 30

genotyping, 30

glycosylation, 30

good clinical practice (GCP), 30

good laboratory practice (GLP), 30

good manufacturing practice (GMP), 30

high-throughput screening, 30

high-resolution mass spectrometry (HR-MS), 31

hit, 31

hit confirmation, 31

hit identification, 31

hit-to-lead/lead generation, 31

$\mathrm{IC}_{50}, 31$

immunocytochemistry, 31

immunogenicity, 31

immunology, 31

immunomodulation, 32

immunotherapy, 32

impurity, 32

in silico, 32

in vitro, 32

in vivo, 32

in-process control, 32

incurred sample, 32

incurred sample reanalysis, 32

informed consent, 33

inhibitory dose, 33

intellectual property, 33

interim data, 33

intermediate, 33
International Organization for

Standardization (ISO), 33

intravascular administration, 33

intrinsic clearance, 33

investigational device exemption, 33

investigational medicinal product (IMP), 34

investigational new drug (IND), 34

investigational new drug (IND) application, 34

ion-exchange chromatography, 34

$\mathrm{Kd}, 34$

$\mathrm{Ki}, 34$

lab-on-a-chip, 34

lead candidate, 34

lead optimization, 35

ligand, 35

ligand-based drug design, 35

ligand efficiency, 35

Lipinski's rule of five (or Pfizer's rule of five or

rule of five or R05), 35

lipophilicity, 35

liposomal drug, 36

liquid chromatography, 36

live-cell imaging, 36

lymphocyte, 36

magnetic-based cell sorting, 36

manufacture, 36

marketing authorization, 36

mass spectrometry, 37

master schedule, 37

matrix, 37

maximum tolerated dose (MTD), 37

mechanism of action, 37

medical device, 37

medicinal product, 37

Medicines and Healthcare products

Regulatory Agency (MHRA), 38

metabolic biomarker, 38

metabolism, 38

metabolite, 38

metabolite profiling, 38 
metabolites in safety testing (MIST), 38 method, 38

microfluidics, 38

microRNA, 39

microsampling, 39

mimetics, 39

minimal manipulation, 39

molecular cloning, 39

molecular docking, 39

monoclonal antibody, 39

multiple ascending dose (MAD), 39

multi-site study, 40

multiplicity of infection (MOI), 40

National Institutes of Health (NIH), 40

National Institute for Health and Care

Excellence (NICE), 40

negative predictive value (NPV), 40

neutralizing antibody (NAb), 40

new drug application (NDA), 40

next-generation sequencing (NGS), 40

non-cell-based neutralizing antibody (NAb)

assay, 40

non-clinical study, 42

non-coding RNA (ncRNA), 42

northern blot, 42

nuclear imaging, 42

off-label use, 42

optical imaging, 42

oral administration, 42

organ-on-a-chip, 42

organoid, 43

orphan drug, 43

orthosteric binding site, 43

orthosteric regulation, 43

paratope, 43

partial agonist, 43

pathogen, 43

peptidomimetic, 43

performance indicator, 43

permeability, 44 pharmaceutical, 44

pharmacodynamics (PD), 44

pharmacoeconomics, 44

pharmacokinetics (PK), 44

pharmacology, 44

pharmacophore, 44

pharmacovigilance, 44

phase I clinical trial, 44

phase II clinical trial, 45

phase III clinical trial, 45

phase IV clinical trial, 45

phosphorylation, 45

photoacoustic imaging, 45

pKa, 45

placebo, 45

placebo-controlled trial, 45

placing on the market, 46

plasma protein binding, 46

polymerase chain reaction (PCR), 46

positive predictive value (PPV), 46

potency, 46

pre-market approval (PMA), 46

preclinical development (PCD), 46

preclinical trial, 46

principal investigator (PI), 47

privileged scaffold, 47

process analytical technology (PAT), 47

prodrug, 47

proof of concept, 47

property-based drug design, 47

protein binding, 47

protein expression, 47

protein therapy, 47

protein-protein interactions (PPIs), 48

proteomics, 48

protocol, 48

protocol amendment, 48

protocol deviation, 48

provenance, 48

purity, 48 
qualification, 48

qualified person (QP), 48

qualified person responsible for

pharmacovigilance (QPPV), 50

quality, 50

quality assurance, 50

quality by design (QbD), 50

quality control (QC), 50

quality control sample, 50

quality system, 51

quantitative/real time polymerase chain

reaction ( $q \mathrm{PCR}), 51$

quantitative structure-activity relationship

(QSAR), 51

raw data, 51

raw material, 51

reactive metabolite, 51

real time release testing (RTRT), 51

reanalysis, 52

recall, 52

receptor, 52

reference standard, 52

regulated bioanalysis, 52

regulatory validation, 52

relative bioavailability, 52

release criteria, 52

repeatability, 53

reproducibility, 53

reverse transcription PCR (RT-PCR), 53

reverse transcription qPCR (RT-qPCR), 53

risk, 53

risk analysis, 53

risk-based approach, 53

risk management, 53

RNA interference (RNAi), 54

RNA sequencing (RNA-Seq), 54

safety, 54

safety follow-up, 54

sample, 54

Sanger sequencing, 54 scaffold, 54

scale out (or scale horizontally), 54

scale up (or scale vertically), 55

serious adverse event (SAE), 55

serious adverse reaction (SAR), 55

sham procedure, 55

side effect, 55

significance, 55

single-cell analysis, 55

single-dose administration, 55

small molecule, 56

solubility, 56

southern blot, 56

specification, 56

specificity, 56

specimen, 56

stability testing, 56

standard operating procedure (SOP), 56

starting material, 57

state of control, 57

steady state, 57

stem cell, 57

structure-activity relationship (SAR), 57

structure based drug design (SBDD), 57

study director, 57

study monitor, 57

study plan, 58

study sample, 58

subject, 58

supplemental new drug application (SNDA), 58

target, 58

target candidate, 58

target validation, 58

telemetric monitoring, 58

the three Rs, 59

therapeutic immunosuppression, 59

therapy, 59

three-dimensional quantitative structure-

activity relationship (3D-QSAR), 59

total drug, 59 
toxicity, 59

toxicology, 59

translation, 60

unexpected adverse reaction (UAR), 60

upstream processing, 60

user requirement brief (URB), 60

user requirement specification (URS), 60

validation, 60

virtual screening, 60

$V_{\text {max }} 60$

western blot, 61

whole bioprocessing, 61

Z' factor, 61 